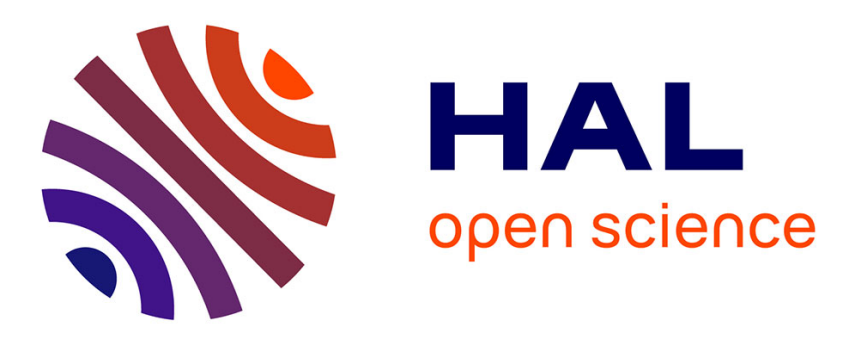

\title{
Simulations of atomic deuterium exposure in self-damaged tungsten
}

\author{
E.A. Hodille, A Založnik, S Markelj, T. Schwarz-Selinger, C.S. Becquart, \\ Régis Bisson, Christian Grisolia
}

\section{- To cite this version:}

E.A. Hodille, A Založnik, S Markelj, T. Schwarz-Selinger, C.S. Becquart, et al.. Simulations of atomic deuterium exposure in self-damaged tungsten. Nuclear Fusion, 2017, 57 (5), pp.056002. 10.1088/17414326/aa5aa5 . hal-01528018

\section{HAL Id: hal-01528018 https://hal-amu.archives-ouvertes.fr/hal-01528018}

Submitted on 14 May 2018

HAL is a multi-disciplinary open access archive for the deposit and dissemination of scientific research documents, whether they are published or not. The documents may come from teaching and research institutions in France or abroad, or from public or private research centers.
L'archive ouverte pluridisciplinaire HAL, est destinée au dépôt et à la diffusion de documents scientifiques de niveau recherche, publiés ou non, émanant des établissements d'enseignement et de recherche français ou étrangers, des laboratoires publics ou privés. 


\title{
Simulations of atomic deuterium exposure in self-damaged tungsten
}

\author{
E.A. Hodille ${ }^{1}$, A. Založnik ${ }^{2}$, S. Markelj ${ }^{2}$, T. Schwarz-Selinger ${ }^{3}$, \\ C.S. Becquart ${ }^{4}$ R. Bisson ${ }^{5}$ and C. Grisolia ${ }^{1}$ \\ ${ }^{1}$ CEA, IRFM, F-13108 Saint-Paul-lèz-Durance, France \\ 2 Jožef Stefan Institute, Jamova cesta 39, 1000, Ljubljana, Slovenia \\ 3 Max-Planck-Institut für Plasmaphysik, Boltzmannstrasse 2, D-85748 Garching, Germany \\ 4 Université Lille I, UMET, UMR 8207, ENSCL, 59655 Villeneuve d'Ascq Cedex, France \\ 5 Aix-Marseille Université, CNRS, PIIM, Marseille, France \\ E-mail: christian.grisolia@cea.fr
}

Received 1 September 2016, revised 12 December 2016

Accepted for publication 4 January 2017

Published 14 March 2017

\begin{abstract}
Simulations of deuterium (D) atom exposure in self-damaged polycrystalline tungsten at $500 \mathrm{~K}$ and $600 \mathrm{~K}$ are performed using an evolution of the MHIMS (migration of hydrogen isotopes in materials) code in which a model to describe the interaction of D with the surface is implemented. The surface-energy barriers for both temperatures are determined analytically with a steady-state analysis. The desorption energy per D atom from the surface is $0.69 \pm 0.02 \mathrm{eV}$ at $500 \mathrm{~K}$ and $0.87 \pm 0.03 \mathrm{eV}$ at $600 \mathrm{~K}$. These values are in good agreement with $a b$ initio calculations as well as experimental determination of desorption energies. The absorption energy (from the surface to the bulk) is $1.33 \pm 0.04 \mathrm{eV}$ at $500 \mathrm{~K}, 1.55 \pm 0.02 \mathrm{eV}$ at $600 \mathrm{~K}$ when assuming that the resurfacing energy (from the bulk to the surface) is $0.2 \mathrm{eV}$. Thermal-desorption spectrometry data after D atom exposure at $500 \mathrm{~K}$ and isothermal desorption at $600 \mathrm{~K}$ after $\mathrm{D}$ atom exposure at $600 \mathrm{~K}$ can be reproduced quantitatively with three bulk-detrapping energies, namely $1.65 \pm 0.01 \mathrm{eV}, 1.85 \pm 0.03 \mathrm{eV}$ and $2.06 \pm 0.04 \mathrm{eV}$, in addition to the intrinsic detrapping energies known for undamaged tungsten $(0.85 \mathrm{eV}$ and $1.00 \mathrm{eV})$. Thanks to analyses of the amount of traps during annealing at different temperatures and $a b$ initio calculations, the $1.65 \mathrm{eV}$ detrapping energy is attributed to jogged dislocations and the $1.85 \mathrm{eV}$ detrapping energy is attributed to dislocation loops. Finally, the $2.06 \mathrm{eV}$ detrapping energy is attributed to D trapping in cavities based on literature reporting observations on the growth of cavities, even though this could also be understood as D desorbing from the C-D bond in the case of hydrocarbon contamination in the experimental sample.
\end{abstract}

Keywords: tungsten, damaged material, rate-equation modeling, deuterium atoms, fuel retention

(Some figures may appear in colour only in the online journal)

\section{Introduction}

Due to its good mechanical and thermal properties, tungsten (W) has been chosen to be the material constituting the divertor region in ITER. This region is the part of the tokamak which experiences the highest particle flux $\left(10^{24} \mathrm{~m}^{-2} \mathrm{~s}^{-1}\right)$ making hydrogen isotope (HI) retention and outgassing from W a key consideration for safety and plasma control issues. During the deuterium/tritium phase in ITER, fast neutrons
(14.1 MeV) will be created. They can transmute the elements present in plasma-facing components (PFCs) [1] and they will also induce crystallographic defects that can change the HI trapping and release properties of all the materials facing the plasma. 14.1 MeV neutron sources are scarce and a hot cell facility is required to deal with neutron-irradiated samples. A good proxy to simulate the damage induced during neutron irradiations has been found in $\mathrm{MeV}$ heavy-ion implantations and especially $\mathrm{MeV} \mathrm{W}$ ions [2], the latter irradiation resulting 
in so-called self-damaged W samples. The interaction of HIs with self-damaged $\mathrm{W}$ has been extensively studied experimentally, particularly in relation to their retention properties [3-8]. These studies show that the D retention in such materials is significantly higher than in undamaged W. In addition, by analyzing thermal-desorption spectrometry (TDS) results, it has been observed that $\mathrm{D}$ is released at a far higher temperature in the case of self-damaged $\mathrm{W}$ than in the case of undamaged $\mathrm{W}[8]$.

In this study, the MHIMS (migration of hydrogen isotopes in metals) [9] code, which is based on a macroscopic rateequation (MRE) model that couples both diffusion and trapping of HIs, has been upgraded to simulate the experimental results presented in $[6,7]$. In these two experimental studies, self-damaged polycrystalline W (PCW) samples were exposed to a beam of deuterium (D) atoms with a low kinetic energy of $\sim 0.3 \mathrm{eV}$. With such a low kinetic energy, D atoms may not directly reach the bulk and be implanted as they would be in the case of energetic D ions. Instead, they are first adsorbed on the W surface $[10,11]$. In order to include this kind of events in simulations, a surface model needs to be built, and one of the goals of this paper is to describe the implementation of such a model in the MHIMS code. The article is organized as follows. First, the model and its main features are described, and then the procedure adopted to determine the different energy barriers at the surface is detailed. Finally, the simulation results obtained using the upgraded version of MHIMS are compared to the experimental studies and discussed.

\section{Simulation of the experimental results}

\subsection{Model description}

In this paper, the MHIMS code that was previously used to determine the trapping parameters of HIs in undamaged PCW irradiated with D ions [9] was upgraded to simulate the two experiments presented in $[6,7]$. In the version of the code presented in [9], no surface effects were taken into account since TDS experiments showed that surface recombination was not the rate-limiting process in the desorption from undamaged PCW implanted with $250 \mathrm{eV} / \mathrm{D}$ ions [12]. However, experimental results by 't Hoen et al [10] showed that the insertion of low energetic ions $(<5 \mathrm{eV} / \mathrm{D})$ is limited by the surface process. Such results were confirmed by molecular dynamics (MD) simulations of D on the W surface by Maya [11]. In these simulations, it was shown that atoms with energy below $1 \mathrm{eV} / \mathrm{D}$ do not penetrate beneath the surface, but are instead stuck on it. Thus, the $0.3 \mathrm{eV} / \mathrm{D}$ atoms used in $[6,7]$ should not be directly implanted into the bulk, but instead should be first adsorbed on the surface. To simulate such exposure conditions, a model describing the different surface processes has been added to the standard version of the MHIMS code.

The model for surface and bulk interaction between HIs and $\mathrm{W}$ can be described with the idealized interaction potential diagram drawn in figure $1[13,14]$. Here, $\frac{1}{2} E_{\text {diss }}$ is the energy barrier per $\mathrm{D}$ atom associated to the dissociative adsorption of $D_{2}$ molecules impinging from the energy level $\frac{1}{2} D_{2}$.
The upper-vacuum energy-level D corresponds to the one of impinging $\mathrm{D}$ atoms. Noth these energy levels are thus separated by half the $\mathrm{D}_{2}$ dissociation energy $\frac{1}{2} E_{\mathrm{D}-\mathrm{D}}$. The activation energy for desorption $E_{\mathrm{des}}$ represents the energy needed to form a desorbing $\mathrm{D}_{2}$ molecule from two chemisorbed $\mathrm{D}$ atoms and can be written as $E_{\text {des }}=2 \cdot E_{\mathrm{D}}$ where $E_{\mathrm{D}}$ is the desorption energy per $\mathrm{D}$ atom [14]. This quantity should not be mistaken with the chemisorption energy $\left(E_{\text {chem }}\right)$ or the isosteric heat of adsorption $\left(q_{\mathrm{st}}\right)$ which are equal to $E_{\mathrm{des}}-E_{\mathrm{diss}}$, nor the bond energy of $\mathrm{D}$ atoms on the surface $\left(E_{\mathrm{W}-\mathrm{D}}\right)$, which is defined as the energy difference between the vacuum energy level of the impinging D and the energy level of D at the bottom of the surface chemisorption well. According to Pick et al [14], the solution energy is defined as the difference between the molecular vacuum energy level and the atomic-bulk adsorption well, i.e. $E_{\mathrm{S}}=E_{\mathrm{A}}-E_{\mathrm{D}}+\frac{1}{2} \cdot E_{\mathrm{diss}}-E_{\mathrm{R}}$ (figure 1), where $E_{\mathrm{A}}$ is the energy needed for an adsorbed D to enter the bulk (absorption energy) and $E_{\mathrm{R}}$ is the energy needed for an absorbed D to go from the bulk to the surface (resurfacing energy). Finally, $E_{\text {diff }}$ is the energy barrier for D diffusion in the bulk and $E_{\mathrm{B}, i}$ is the binding energy of D with a trap of type $i i$ (in figure $1, i=1,2$ ).

To build the model, three kinds of particles (i.e. HIs) are considered:

1. Particles adsorbed on the surface: concentration $c_{\text {surf }}$. $\left(\mathrm{m}^{-2}\right)$.

2. Mobile particles that can diffuse in the bulk: concentration $c_{\mathrm{m}} \cdot\left(\mathrm{m}^{-3}\right)$.

3. Particles trapped in the bulk: concentration $c_{\mathrm{t}, i} \cdot\left(\mathrm{m}^{-3}\right)$. Several types of traps exist, characterized by their index $i$.

The finite amount of sites that can accommodate HIs are of three kinds:

1. Adsorption sites on the surface: concentration $n_{\text {surf }}\left(\mathrm{m}^{-2}\right)$. 2. Interstitial sites in the bulk: concentration $n_{\mathrm{TIS}}\left(\mathrm{m}^{-3}\right)$. Indeed, density functional theory (DFT) calculations show that interstitial HIs diffuse from tetrahedral interstitial sites (TIS) [15] to nearest-neighbor TIS.

3. Trapping sites in the bulk: concentration $n_{\mathrm{i}}\left(\mathrm{m}^{-3}\right)$.

As shown above, all bulk concentrations are in $\mathrm{m}^{-3}$ in the model. However, in experimental results these are often expressed in terms of percentage of atomic fraction (at.\%) by normalizing concentrations to the $\mathrm{W}$ atomic density $\rho_{\mathrm{W}} \approx 6.3 \times 10^{28} \mathrm{~m}^{-3}$. Thus, in the simulation results shown here, the concentration will also sometimes be expressed in at. $\%$.

In the following, it is supposed that the amount of traps is small compared to the amount of possible sites for the mobile particles ( $\left.n_{\mathrm{i}} \ll n_{\text {TIS }}\right)$. Thus, each trap site is surrounded by only TIS and a HI leaving a trap cannot be immediately retrapped in another trap. In addition, it is considered that the concentration of mobile particles is much smaller than the concentration of TIS ( $c_{\mathrm{m}} \ll n_{\mathrm{TIS}}$ ). Thus, among all the TIS that surround a trapping site, there is at least one of them that is empty. This hypothesis is always valid for the parameter range encountered in laboratory experiments. Following these two 


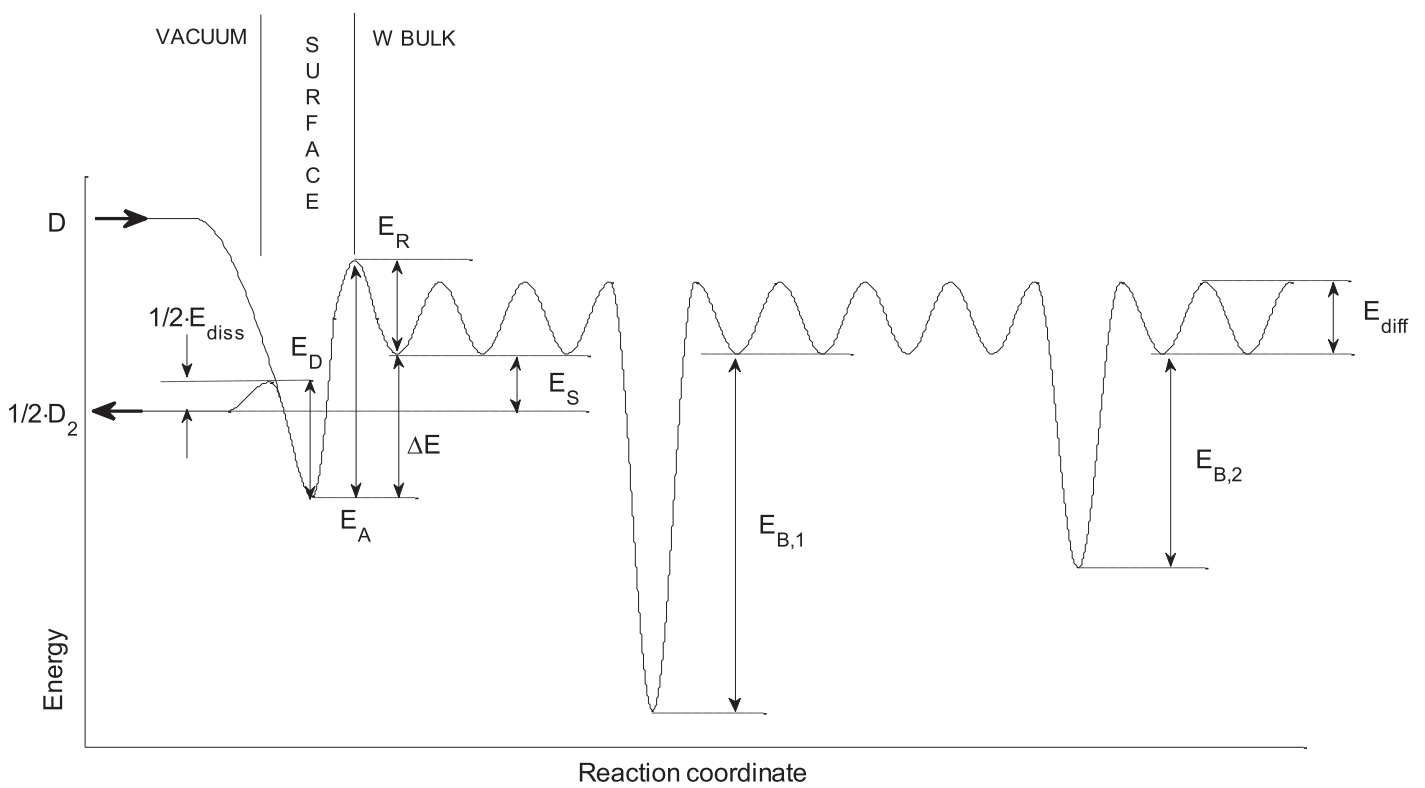

Figure 1. Idealized potential diagram describing the interaction of HIs with $\mathrm{W}$ at the surface (interface between the vacuum and the metal) and in the bulk.

hypotheses, the evolution of the concentration of trapped and mobile particles in the bulk can be defined by the following commonly used set of equations [16]:

$$
\begin{gathered}
\frac{\partial c_{\mathrm{m}}}{\partial t}=D(T) \cdot \frac{\partial^{2} c_{\mathrm{m}}}{\partial x^{2}}-\Sigma \frac{\partial c_{\mathrm{t}, i}}{\partial t} \\
\frac{\partial c_{\mathrm{t}, i}}{\partial t}=\nu_{\mathrm{m}}(T) \cdot c_{\mathrm{m}} \cdot\left(n_{\mathrm{i}}-c_{\mathrm{t}, i}\right)-\nu_{\mathrm{i}}(T) \cdot c_{\mathrm{t}, i} .
\end{gathered}
$$

The first term on the right-hand side of equation (1) is derived from Fick's law of diffusion and is characterized by the diffusion coefficient of HIs in $\mathrm{W}, D(T)=D_{0} \cdot \mathrm{e}^{-\frac{E_{\mathrm{diff}}}{k_{\mathrm{B}} \cdot T}},\left(\mathrm{~m}^{2} \mathrm{~s}^{-1}\right)$ where $k_{\mathrm{B}}=8.6 \times 10^{-5} \mathrm{eV} \cdot \mathrm{K}^{-1}$ is the Boltzmann constant, $T$ $(\mathrm{K})$ is the sample temperature and $E_{\text {diff }}(\mathrm{eV})$ is the energy barrier for diffusion (figure 1). For this study, the diffusion coefficient for hydrogen calculated using DFT by Fernandez et al [15] is used: $D_{\mathrm{H}}(T)=1.9 \times 10^{-7} \cdot \mathrm{e}^{-\frac{0.2 \mathrm{eV}}{k_{\mathrm{B}} \cdot T}} \mathrm{~m}^{2} \cdot \mathrm{s}^{-1}$. The diffusion coefficient of $\mathrm{D}$ is equal to $D_{\mathrm{H}}(T)$ divided by $\sqrt{2}$, the square root of the atomic mass ratio between $D$ and $\mathrm{H}$. The second term on the right-hand side of equation (1) corresponds to the exchange (trapping and detrapping) between mobile and trapped particles that is described by equation (2) for trap type $i$. In equation (2), the first term of the righthand side corresponds to the trapping of mobile particles into an empty trap site $\left(n_{\mathrm{i}}-c_{\mathrm{t}, i}\right)$. This process is characterized by the rate $\nu_{\mathrm{m}}(T)=\frac{D(T)}{n_{\mathrm{TIS}} \cdot \lambda^{2}}\left(\mathrm{~m}^{3} \mathrm{~s}^{-1}\right)$ where $\lambda$ is the distance between 2 TIS or the jumping distance. This can be estimated to be $\lambda \approx 110 \times 10^{-12} \mathrm{~m}$ from ab initio calculations [15]. The second term of equation (2) corresponds to the detrapping of a trapped particle. This process is characterized by the rate $\nu_{\mathrm{i}}(T)=\nu_{0} \cdot \mathrm{e}^{-\frac{E_{\mathrm{t}, i}}{k_{\mathrm{B}} \cdot T}}\left(\mathrm{~s}^{-1}\right)$ where $E_{\mathrm{t}, i}=E_{\mathrm{B}, i}+E_{\mathrm{diff}} \cdot(\mathrm{eV})$ is the detrapping energy of trap site $i$ and $\nu_{0}$ is a pre-exponential factor. The value of the pre-exponential factor is important to know (at least its order of magnitude). Indeed, a change

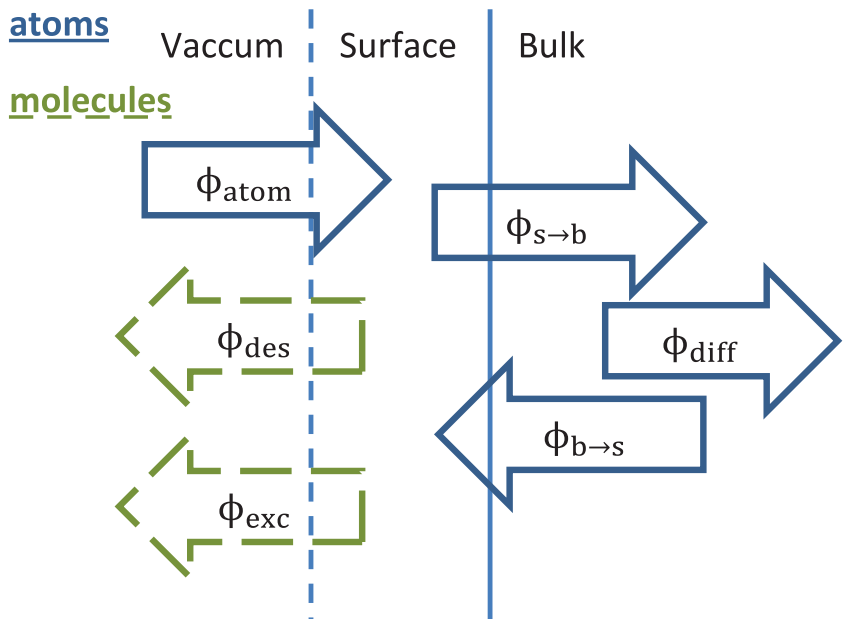

Figure 2. Explicative scheme of the flux balance on the surface. Blue solid arrows correspond to flux of atoms and green dashed arrows correspond to flux of molecules.

of one order of magnitude on this pre-exponential factor will lead to a change of $\approx k_{\mathrm{B}} \cdot T \cdot \ln (10)$ on the determination of the detrapping energy. For the simulation of a TDS experiment done between $300 \mathrm{~K}$ and $1300 \mathrm{~K}$, the corresponding error would be between 0.05 and $0.25 \mathrm{eV}$. According to firstprinciples calculations [15], the pre-exponential factor for detrapping of $\mathrm{H}$ from a W mono-vacancy is $\nu_{0} \approx 10^{13} \mathrm{~s}^{-1}$ and this is the order of magnitude which is used for several MRE simulations [5, 9] and which is used for this work too.

The model for the surface, acting as boundary conditions for the global MRE model, is described by the evolution of $c_{\mathrm{m}}(x=0)$ and $c_{\text {surf }}$. The surface coverage is $\theta=\frac{c_{\text {surf }}}{n_{\text {surf }}}$. This defines the amount of adsorption sites that are occupied: $(1-\theta)$ is the probability that an adsorption site is empty. The evolutions of the two quantities $c_{\mathrm{m}}(x=0)$ and $c_{\text {surf }}$ are driven by different fluxes $\left(\mathrm{m}^{-2} \mathrm{~s}^{-1}\right)$ which are described hereafter (see figure 2 ): 
$-\phi_{\text {atom }}=\left(1-P_{\mathrm{r}}\right) \cdot \Gamma_{\text {atom }} \cdot(1-\theta)$. This corresponds to the part of the incident flux of atoms $\Gamma_{\text {atom }}\left(\mathrm{m}^{-2} \mathrm{~s}^{-1}\right)$ adsorbed on the surface. The term $1-\theta$ implies that a fully covered surface prevents any incoming $\mathrm{D}$ atoms from being adsorbed. $\left(1-P_{\mathrm{r}}\right)$ is the sticking probability. According to MD simulations $[17,18]$ the sticking coefficient of a $0.3 \mathrm{eV} \mathrm{D}$ atom on a pristine $\mathrm{W}$ surface is $\left(1-P_{\mathrm{r}}\right)=0.19$ which is the value used in the equation $\left(P_{\mathrm{r}}\right.$ is not a free parameter) and is also in good agreement with the value determined experimentally [6].

$-\phi_{\text {exc }}=\Gamma_{\text {atom }} \cdot \sigma_{\text {exc }} \cdot c_{\text {surf }}$. This corresponds to direct abstraction of a chemisorbed $\mathrm{D}$, i.e. the recombination of an incident $\mathrm{D}$ atom with an adsorbed atom on the surface [6] which is characterized by the cross-section $\sigma_{\mathrm{exc}}$ $\left(\mathrm{m}^{2}\right)$. The value of $\sigma_{\text {exc }}$. that is used in this work is the one determined in [6] to reproduce an isotopic exchange experiment on the surface: $\sigma_{\mathrm{exc}} \approx 10^{-21} \mathrm{~m}^{2}\left(\sigma_{\mathrm{exc}}\right.$ is not a free parameter).

$-\phi_{\text {desorb }}=2 \cdot \nu_{\mathrm{d}}(T) \cdot c_{\text {surf }}^{2}$. This corresponds to desorption of $\mathrm{D}$ atoms from the surface as molecules. The desorption rate constant is $\nu_{\mathrm{d}}(T)=\nu_{0}^{\mathrm{d}} \cdot \lambda_{\text {des }}^{2} \cdot \mathrm{e}^{-\frac{2 \cdot E_{\mathrm{D}}}{k_{\mathrm{B}} \cdot T}}\left(\mathrm{~m}^{2} \mathrm{~s}^{-1}\right)$ where $\nu_{0}^{\mathrm{d}}$ is the frequency associated to desorption and $\lambda_{\text {des }}(\mathrm{m})$ is the jumping distance between two surface-adsorption sites. This can be estimated to be $\lambda_{\text {des }}=\frac{1}{\sqrt{n_{\text {surf }}}}$.

$-\phi_{\text {bulk } \rightarrow \text { surf }}=\nu_{\mathrm{sb}}(T) \cdot c_{\text {surf }}$. This corresponds to the absorption of a D adatom from the surface to the bulk (with the assumption of low mobile concentration). The absorption rate constant is $\nu_{\mathrm{sb}}(T)=\nu_{0}^{\mathrm{sb}} \cdot \mathrm{e}^{-\frac{E_{\mathrm{A}}}{k_{\mathrm{B}} T}}\left(\mathrm{~s}^{-1}\right)$ with $\nu_{0}^{\mathrm{sb}}$ the frequency associated to absorption.

$-\phi_{\text {bulk } \rightarrow \text { surf }}=\nu_{\mathrm{bs}}(T) \cdot c_{\mathrm{m}}(x=0) \cdot(1-\theta)$. This corresponds to the release of a D atom from the bulk to the surface (resurfacing). The surface becomes inactive once it is fully covered by $\mathrm{D}$ atoms $(1-\theta=0)$. The rate constant for this process is $\nu_{\mathrm{bs}}(T)=\nu_{0}^{\mathrm{bs}} \cdot \lambda_{\mathrm{abs}} \cdot \mathrm{e}^{-\frac{E_{\mathrm{R}}}{k_{\mathrm{B}} \cdot T}}\left(\mathrm{~m}^{1} \mathrm{~s}^{-1}\right)$ with $\nu_{0}^{\text {bs }}$ the frequency associated to resurfacing and $\lambda_{\text {abs }}$ (m) the jumping distance between the first TIS that the HI encounters in the bulk and the adsorption site. It can be estimated to be $\lambda_{\text {abs }}=\frac{n_{\text {surf }}}{n_{\text {TIS }}}$.

$-\phi_{\text {diff }}=-D(T) \cdot\left(\frac{\partial c_{\mathrm{m}}}{\partial x}\right)_{x=0}$. This corresponds to the diffusion of the absorbed D atom from the first bulk TIS below the surface $(x=0)$ to deeper in the bulk $(x>0)$.

Regarding the pre-exponential factor, the same remark as for the detrapping process applies here: a change of one order of magnitude can affect the value of the different energies $\left(E_{\mathrm{A}}\right.$, $E_{\mathrm{D}}$ and $\left.E_{\mathrm{R}}\right)$ by about $0.1 \mathrm{eV}$ for exposure at $500 \mathrm{~K}$ and $600 \mathrm{~K}$. According to different authors $[6,19,20]$, the pre-exponential factor for desorption used to reproduce experimental measurements is $0.01 \mathrm{~cm}^{2} \cdot \mathrm{s}^{-1}>\lambda_{\text {des }}^{2} \cdot \nu_{0}^{\mathrm{d}}>0.001 \mathrm{~cm}^{2} \cdot \mathrm{s}^{-1}$. A value of $\lambda_{\text {des }}$ of the order of $0.2 \mathrm{~nm}$ ( interatomic distance in the $\mathrm{W}$ lattice) and $\nu_{0}^{\mathrm{d}}=10^{13} \mathrm{~s}^{-1}$ leads to $\lambda_{\mathrm{des}}^{2} \cdot \nu_{0}^{\mathrm{d}}=0.004 \mathrm{~cm}^{2} \cdot \mathrm{s}^{-1}$. As a consequence, it is assumed $\nu_{0}^{\mathrm{d}}=10^{13} \mathrm{~s}^{-1}$. It is also assumed that $\nu_{0}^{\mathrm{sb}}=\nu_{0}^{\mathrm{bs}}=10^{13} \mathrm{~s}^{-1}$, which is the order of magnitude of what is calculated with the harmonic transition-state theory for these adsorption and resurfacing processes [21].
The evolution of $c_{\mathrm{m}}(x=0)$ and $c_{\text {surf }}$ is then described by the balance of fluxes (figure 2) as follows:

$$
\begin{gathered}
\frac{\partial \mathrm{c}_{\text {surf }}}{\partial t}=\phi_{\text {atom }}-\phi_{\text {exc }}-\phi_{\text {desorb }}-\phi_{\text {surf } \rightarrow \text { bulk }}+\phi_{\text {bulk } \rightarrow \text { surf }} \\
\lambda \cdot\left(\frac{\partial c_{\mathrm{m}}}{\partial t}\right)_{x=0}=\phi_{\text {surf } \rightarrow \text { bulk }}-\phi_{\text {bulk } \rightarrow \text { surf }}-\phi_{\text {diff }}
\end{gathered}
$$

The different parameters of the surface and bulk models are summarized in table 1 . The values used for the non-free parameters are also given in table 1 . The parameters that need to be determined are called 'free' parameters.

\subsection{Steady-state analysis and determination of surface-energy barriers}

Equations (1) and (2) give a general description of the model in the bulk and equations (3) and (4) describe the model for the surface. This set of equations are solved numerically using the code to simulate the experimental results (sections 2.3 and 2.4). Before going into the details of the simulations, a steadystate analysis and a simplified model is presented in this section that intends to define a strategy which will allow us to determine the surface-energy barriers.

In order to understand the main features of the model, the steady states of equations (3) and (4) are investigated when $\frac{\partial c_{\text {surf }}}{\partial t}=0$ and $\left(\frac{\partial c_{\mathrm{m}}}{\partial t}\right)_{x=0}=0$. In addition, it is considered that the diffusive flux of particles from the sub-surface to the bulk $\phi_{\text {diff }}$ is negligible (i.e. $\left(\frac{\partial c_{\mathrm{m}}}{\partial x}\right)_{x=0}=0$ ) in order to simplify the approach. It can be shown by simulation that this flux is, indeed, not dominant. The steady-state regime is characterized by constant values of $c_{\mathrm{m}}(x=0)$ and $c_{\text {surf }}$ (and so $\theta$.) written as $c_{\mathrm{m}}^{\mathrm{eq}}, c_{\text {surf }}^{\mathrm{eq}}$ and $\theta^{\mathrm{eq}}$.

Following this assumption, a relation between $c_{\mathrm{m}}(x=0)$ and $c_{\text {surf }}$ can be derived from equation (4) in the steady state:

$$
c_{\mathrm{m}}^{\mathrm{eq}}(x=0)=\frac{\nu_{\mathrm{sb}}(T)}{\nu_{\mathrm{bs}}(T)} \cdot \frac{c_{\mathrm{surf}}^{\mathrm{eq}}}{1-\theta^{\mathrm{eq}}} .
$$

Using this relation in equation (3) in the steady state, with $\theta^{\text {eq }}=\frac{c_{\text {surf }}^{\text {eq }}}{n_{\text {surf }}}$ and assuming $\frac{\partial c_{\text {surf }}}{\partial t}=0$, we have the following relation:

$$
-2 \cdot v_{\mathrm{d}}(T) \cdot\left(c_{\text {surf }}^{\mathrm{eq}}\right)^{2}-\omega_{1} \cdot c_{\text {surf }}^{\mathrm{eq}}+\omega_{2}=0
$$

with $\omega_{1}=\Gamma_{\text {atom }} \cdot\left(\frac{\left(1-P_{\mathrm{r}}\right)}{n_{\text {surf }}}+\sigma_{\text {exc }}\right)$ and $\omega_{2}=\left(1-P_{\mathrm{r}}\right) \cdot \Gamma_{\text {atom }}$.

These quantities are introduced only to simplify the notations.

By solving equation (6), the value of $c_{\text {surf }}^{\mathrm{eq}}$ can be calculated:

$$
c_{\mathrm{surf}}^{\mathrm{eq}}=\frac{\sqrt{\omega_{1}^{2}+8 \cdot \nu_{\mathrm{d}}(T) \cdot \omega_{2}}-\omega_{1}}{4 \cdot \nu_{\mathrm{d}}(T)} .
$$

If $v_{\mathrm{d}}(T) \rightarrow 0$ (no desorption of molecules) or $\Gamma_{\mathrm{atom}} \rightarrow \infty$ (high flux), the surface concentration is $c_{\text {surf }}^{\text {eq }} \rightarrow c_{\text {surf }}^{\infty}=$ $\frac{\omega_{2}}{\omega_{1}}=n_{\text {surf }} \cdot \frac{1-P_{\mathrm{r}}}{1-P_{\mathrm{r}}+\sigma_{\mathrm{exc}} \cdot n_{\text {surf }}}$. If $\sigma_{\mathrm{exc}}=0$ (no abstraction), this concentration is $n_{\text {surf }}$. In the case of a non-negligible abstraction, 
Table 1. Summary of the parameters used in the bulk and surface models.

\begin{tabular}{|c|c|c|c|}
\hline$\Gamma_{\text {atom }}$ & Incident flux of $0.3 \mathrm{eV} \mathrm{D}$ atoms & $\begin{array}{l}\text { As in the simulated experiments: } \\
2.6 \times 10^{19} \mathrm{Dm}^{-2} \mathrm{~s}^{-1} \\
5.8 \times 10^{18} \mathrm{Dm}^{-2} \mathrm{~s}^{-1}\end{array}$ & $\begin{array}{l}{[7]} \\
{[6]}\end{array}$ \\
\hline $1-P_{\mathrm{r}}$ & Sticking probability of D atoms & 0.19 for $0.3 \mathrm{eV} / \mathrm{D}$ atoms & {$[17,18]$} \\
\hline$\sigma_{\mathrm{exc}}$ & Cross-section associated to the direct abstraction process & $1.7 \times 10^{-21} \mathrm{~m}^{-2}$ & [6] \\
\hline$D_{\mathrm{H}}(T)$ & Diffusion coefficient & $1.9 \times 10^{-7} \cdot \mathrm{e}^{-\frac{0.2(\mathrm{eV})}{k_{\mathrm{B}} \cdot T}}$ in $\mathrm{m}^{2} \mathrm{~s}^{-1}$ & {$[15]$} \\
\hline$n_{\mathrm{TIS}}$ & Concentration of TIS & $6 \cdot \rho_{\mathrm{W}}\left(\mathrm{m}^{-3}\right)$ & [15] \\
\hline$n_{\text {surf }}$ & Concentration of adsorption sites & $6.9 \cdot \rho_{\mathrm{W}}^{2 / 3}\left(\mathrm{~m}^{-2}\right)$ & [6] \\
\hline$\lambda$ & Jumping distance between two TIS & $110 \times 10^{-12} \mathrm{~m}$ & [15] \\
\hline$\overline{\lambda_{\text {des }}}$ & Jumping distance between two adsorption sites & $\frac{1}{\sqrt{n_{\text {surf }}}}(\mathrm{m})$ & \\
\hline$\overline{\lambda_{\mathrm{abs}}}$ & $\begin{array}{l}\text { Jumping distance between the first bulk TIS and an } \\
\text { adsorption site }\end{array}$ & $\frac{n_{\text {surf }}}{n_{\mathrm{TIS}}}(\mathrm{m})$ & \\
\hline $\begin{array}{l}\nu_{0} \\
\nu_{0}^{\mathrm{d}} \\
\nu_{0}^{\mathrm{sb}}\end{array}$ & $\begin{array}{l}\text { Pre-exponential frequency factors for detrapping, } \\
\text { desorption, absorption and resurfacing processes }\end{array}$ & $10^{13} \mathrm{~s}^{-1}$ & $\begin{array}{l}{[6,15,19,} \\
20,21]\end{array}$ \\
\hline$\underline{\nu_{0}^{\mathrm{bs}}}$ & & & \\
\hline$E_{\text {diss }}$ & Activation energy for $\mathrm{D}_{2}$ molecule adsorption & $0.0 \mathrm{eV}$ & {$[39,40]$} \\
\hline$\overline{E_{\mathrm{D}}}$ & $\begin{array}{l}\text { Desorption energy per } \mathrm{D} \text { (=half the activation energy for } \\
\text { desorption) }\end{array}$ & Free parameter $(\mathrm{eV})$ & \\
\hline$\overline{E_{\mathrm{A}}}$ & $\begin{array}{l}\text { Activation energy for absorption from the surface to } \\
\text { the bulk }\end{array}$ & Free parameter $(\mathrm{eV})$ & \\
\hline$E_{\mathrm{R}}$ & Activation energy for resurfacing from the bulk to the surface & Free parameter $(\mathrm{eV})$ & \\
\hline$E_{\mathrm{t}, i}$ & $\begin{array}{l}=E_{\mathrm{B}, i}+E_{\mathrm{diff}} \\
\text { Detrapping energy from trap } i\end{array}$ & Free parameter $(\mathrm{eV})$ & \\
\hline$\overline{n_{i}}$ & Concentration of trap sites $i$ & Free parameter $\left(\mathrm{m}^{-3}\right.$ or at. $\left.\%\right)$ & \\
\hline
\end{tabular}

the maximum surface concentration is smaller than the concentration of surface sites $n_{\text {surf }}$ depending on the efficiency of the direct abstraction.

According to equation (5), the steady-state concentration of mobile particles $c_{\mathrm{m}}^{\mathrm{eq}}(x=0)$ depends on the surface concentration and on the competition between absorption of HI atoms from the surface to the bulk and resurfacing of HI atoms from the bulk to the surface: the value of $c_{\mathrm{m}}^{\mathrm{eq}}$ does not depend on the values of $E_{\mathrm{A}}$ and $E_{\mathrm{R}}$. but on the difference $\Delta E=E_{\mathrm{A}}-E_{\mathrm{R}}$ since $\frac{\nu_{\mathrm{sb}}(T)}{\nu_{\mathrm{bs}}(T)}=\frac{1}{\lambda_{\mathrm{abs}}} \cdot \mathrm{e}^{-\frac{\left(E_{\mathrm{A}}-E_{\mathrm{R}}\right)}{k_{\mathrm{B}} \cdot T}}$. However, the values of $E_{\mathrm{A}}$ and $E_{\mathrm{R}}$ have an impact on the kinetics to reach this equilibrium.

According to equation (7), the steady-state concentration of HIs $c_{\text {surf }}^{\text {eq }}$ on the surface depends only on the desorption energy per $\mathrm{D}$ atom $E_{\mathrm{D}}$ and on the flux of atoms. Using both equations (5) and (7), each couple of $\left(\Delta E, E_{\mathrm{D}}\right)$ leads to a direct and unique equivalence between the incident flux of atoms $\Gamma_{\text {atom }}$ and the concentration of mobile atoms below the surface $c_{\mathrm{m}}^{\mathrm{eq}}$.

After looking at the steady-state equations describing the W/HI interactions at the surface, one can look at the steady state of equation (2), which describes the kinetic equilibrium between mobile and trapped particles in the bulk. In the steadystate, the equilibrium concentration of trapped particle $c_{\mathrm{t}, i}^{\mathrm{eq}}$ in trap $i$ can be expressed as follows: $c_{\mathrm{t}, i}^{\mathrm{eq}}=R_{\mathrm{trap}, i}\left(T, c_{\mathrm{m}}\right) \cdot n_{\mathrm{i}}$ with

$$
R_{\text {trap }, i}=\frac{1}{1+\frac{\nu_{\mathrm{i}}(T)}{\nu_{\mathrm{m}}(T) \cdot c_{\mathrm{m}}}} .
$$

The equilibrium ratio defined in equation (8) exhibits competition between detrapping and trapping processes described by the characteristic detrapping time $\frac{1}{\nu_{i}(T)}$ and the characteristic trapping time $\frac{1}{\nu_{\mathrm{m}}(T) \cdot c_{\mathrm{m}}}$, respectively. If the trapping process is faster than the detrapping process $\left(\nu_{\mathrm{m}}(T) \cdot c_{\mathrm{m}} \gg \nu_{i}\right), R_{\text {trap }, i}$ will be close to 1 and almost all the traps will be filled. This is the case for low temperature ( $\operatorname{small} \nu_{i}(T)$ ) or high flux (high $c_{\mathrm{m}}$ ) exposure. Indeed, equations (5) and (7) show that a simple equivalence between the flux of particles and the concentration of mobile particles can be established and the concentration of mobile particles just beneath the surface increases with the atom flux $\Gamma_{\text {atom. }}$. Due to the diffusion, the mobile particles that are inserted just beneath the surface migrate to the bulk making $c_{\mathrm{m}}(x=0)$, the maximum of the concentration of mobile particles. This concentration of mobile particles is called $c_{\mathrm{m}}^{\mathrm{MAX}}=c_{\mathrm{m}}^{\mathrm{eq}}(x=0)$ in the steady state of equations (3) and (4). To characterize the migration of mobile particles into the bulk from a surface source of mobile particles (described by $c_{\mathrm{m}}^{\mathrm{MAX}}$ ) a simple analytical model can be used, as first 

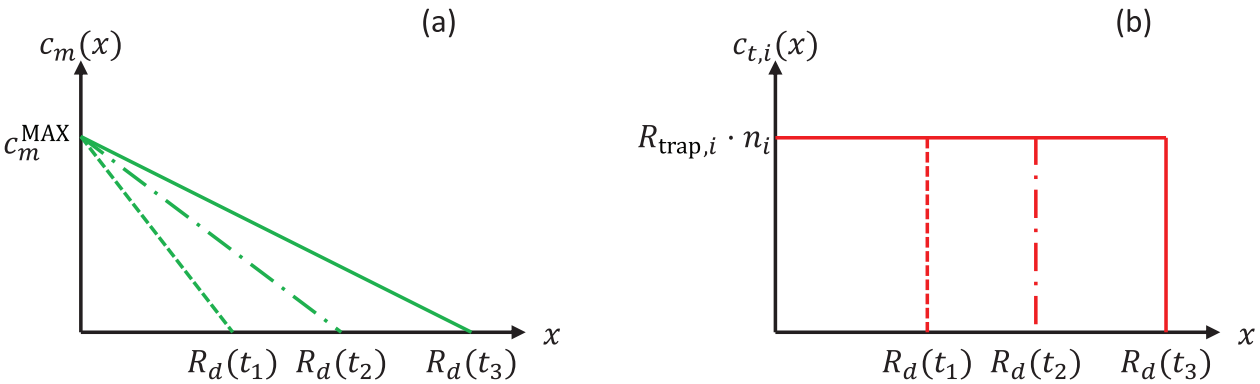

Figure 3. (a) Evolution of mobile particle during atomic exposure at three times $t_{1}, t_{2}$ and $t_{3}$ using the approximated model. (b) Evolution of the concentration of trapped particles in trap $i$ using the approximated model.

reported by Schmid et al [22], to understand the time evolution of the outgassing flux of molecules after the implantation of $\mathrm{D}$ ions. In this model, the evolution of the profile of mobile particles for three different times $t_{1}<t_{2}<t_{3}$ can be described as a gradient from the source to the migration depth $R_{\mathrm{d}}(t)$ at each time $t_{i=1,2,3}$ (figure 3(a)). Assuming that, for the considered trap, $R_{\text {trap }, i}\left(T, c_{\mathrm{m}}\right) \approx 1$, then $R_{\text {trap }, i}$ evolves weakly with $c_{\mathrm{m}}$. We then assume that $R_{\text {trap }, i}\left(T, c_{\mathrm{m}}^{\mathrm{MAX}}\right) \approx R_{\text {trap }, i}\left(T, c_{\mathrm{m}}\right)$. In this case, the profile of trapped particles can be defined by figure $3(b)$. The quantity of particles that are trapped in any of the traps considered after an exposure of $t$ time is:

$$
\operatorname{Tot}_{\text {trap }}(t)=R_{d}(t) \cdot \sum_{i} R_{\text {trap }, i}\left(T, c_{\mathrm{m}}^{\mathrm{MAX}}\right) \cdot n_{i}
$$

In this interpretation, the D inventory in the material is understood as a succession of layers with a constant concentration $\Sigma_{i} R_{\text {trap }, i}\left(T, c_{\mathrm{m}}^{\mathrm{MAX}}\right) \cdot n_{i}$ that pile up to the depth $R_{\mathrm{d}}(t)$ when the exposure time $t$ increases, as suggested by Grisolia et al [23] who used a similar interpretation to describe the D inventory growth in Tore Supra plasma-facing components.

The traps are filled by the flux of particles $\phi_{\text {bulk }}=$ $\phi_{\text {diff }}=D(T) \cdot \frac{c_{\mathrm{m}}^{\mathrm{MAX}}}{R_{\mathrm{d}}(t)}$ diffusing from the surface to the bulk:

$$
\phi_{\text {bulk }}=\frac{\mathrm{dTot}_{\text {trap }}}{\mathrm{d} t}=\frac{\mathrm{d} R_{d(t)}}{\mathrm{d} t} \cdot \sum_{i} R_{\text {trap }, i}\left(T, c_{\mathrm{m}}^{\mathrm{MAX}}\right) \cdot n_{i} .
$$

From this formula, it can be written

$$
R_{\mathrm{d}}(t) \cdot \mathrm{d} R_{\mathrm{d}}(t)=D(T) \cdot \frac{c_{\mathrm{m}}^{\mathrm{MAX}}}{\sum_{i} R_{\mathrm{trap}, i}\left(T, c_{\mathrm{m}}^{\mathrm{MAX}}\right) \cdot n_{i}} \cdot \mathrm{d} t .
$$

Finally, the evolution of the migration depth with time in this crude model is described by equation (9):

$$
R_{\mathrm{d}}(t)=\sqrt{\frac{2 \cdot D(T) \cdot c_{\mathrm{m}}^{\mathrm{MAX}}}{\sum_{i} R_{\mathrm{trap}, i}\left(T, c_{\mathrm{m}}^{\mathrm{MAX}}\right) \cdot n_{i}}} \cdot t .
$$

With the steady-state equations (5) and (7) and the relation derived from the simple model equation (9), the different energy barriers at the surface can be estimated based on experimental observations. The method can be described as follows.

First, if the surface concentration $c_{\text {surf }}$ can be deduced from nuclear reaction analysis (NRA), depth profile analysis or elastic recoil detection analysis (ERDA) measurements [6], and assuming that it corresponds to $c_{\text {surf }}^{\mathrm{eq}}$, the value of $E_{\mathrm{D}}$ can be calculated with equation (7). $n_{\text {surf }}$ is also needed. It can be obtained by loading atoms on the surface at low temperature, which would likely saturate any adsorption sites. In [6], a self-damaged W sample of a different grade has been exposed to $\mathrm{D}$ atoms at $380 \mathrm{~K}$. The $\mathrm{D}$ surface areal density, measured by ERDA, was found to be $11 \pm 1.5 \times 10^{19} \mathrm{D} \cdot \mathrm{m}^{-2}$. For our analysis, we consider this value to be a good approx-

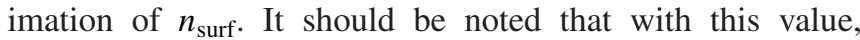
$n_{\text {surf }} \approx(6.9 \pm 1) \times \rho_{\mathrm{W}}^{2 / 3}$, which means that there are 6.9 adsorption sites per $\mathrm{W}$ atom on the surface. The maximum surface coverage on a clean, flat (110) surface has been experimentally determined to be two monolayers (only two adsorption sites per $\mathrm{W}$ atoms) at $180 \mathrm{~K}$ [24]. However, in the experiments we are modelling, the $\mathrm{W}$ surfaces are not clean single crystals (110), but polycrystalline samples exposing a large variety of grain cuts that may show numerous adsorption sites due to the self-damaging. Indeed, it has been shown by Markelj et al [20] that the D surface areal density measured by ERDA at low temperature (below $380 \mathrm{~K}$ ) is much higher on damaged $\mathrm{W}\left(11 \pm 1.5 \times 10^{19} \mathrm{D} \cdot \mathrm{m}^{-2}\right)$ than on undamaged $\mathrm{W}$ $\left(6.8 \pm 0.6 \times 10^{19} \mathrm{D} \cdot \mathrm{m}^{-2}\right)$. It should be pointed out that if it is considered that $n_{\text {surf }}=6.8 \times 10^{19} \mathrm{D} \cdot \mathrm{m}^{-2}$, this would imply a shift of only $0.01 \mathrm{eV}$ on the determination of the value of $E_{\mathrm{D}}$.

Second, from the experimental depth profile, values of $R_{\mathrm{d}}\left(t_{\mathrm{exposure}}\right)$ and $\sum_{i} R_{\mathrm{trap}, i} \cdot n_{i}$ are collected. The quantity $\sum_{i} R_{\text {trap }, i} \cdot n_{i}$ is close to the observed concentration of $\mathrm{D}$ since the mobile particle concentration is always small (no information on the trap concentrations or detrapping energies is needed). Using these two quantities $c_{\mathrm{m}}^{\mathrm{MAX}}$ can be determined using equation (9).

Finally, by equalizing $c_{\mathrm{m}}^{\mathrm{eq}}(x=0)$ given by equation (5) and $c_{\mathrm{m}}^{\mathrm{MAX}}$ calculated thanks to equation (9), the value of $\Delta E$ can be extracted. This procedure allows us to determine the difference in energy barriers at the surface/bulk interface analytically and this procedure will be used for both exposure temperatures $500 \mathrm{~K}$ and $600 \mathrm{~K}$. Thus, in the simulation, only the bulk detrapping energies and the trap densities remain to be determined to reproduce the isothermal desorption, the depth profile and the TDS spectra.

\subsection{Simulation of $D$ atom implantation at $500 \mathrm{~K}$}

The upgraded version of MHIMS is used to simulate experiments published by Zaloznik et al [7]. In this study, recrystallized PCW $(2000 \mathrm{~K} / 2 \mathrm{~min})$ was used. The samples were 

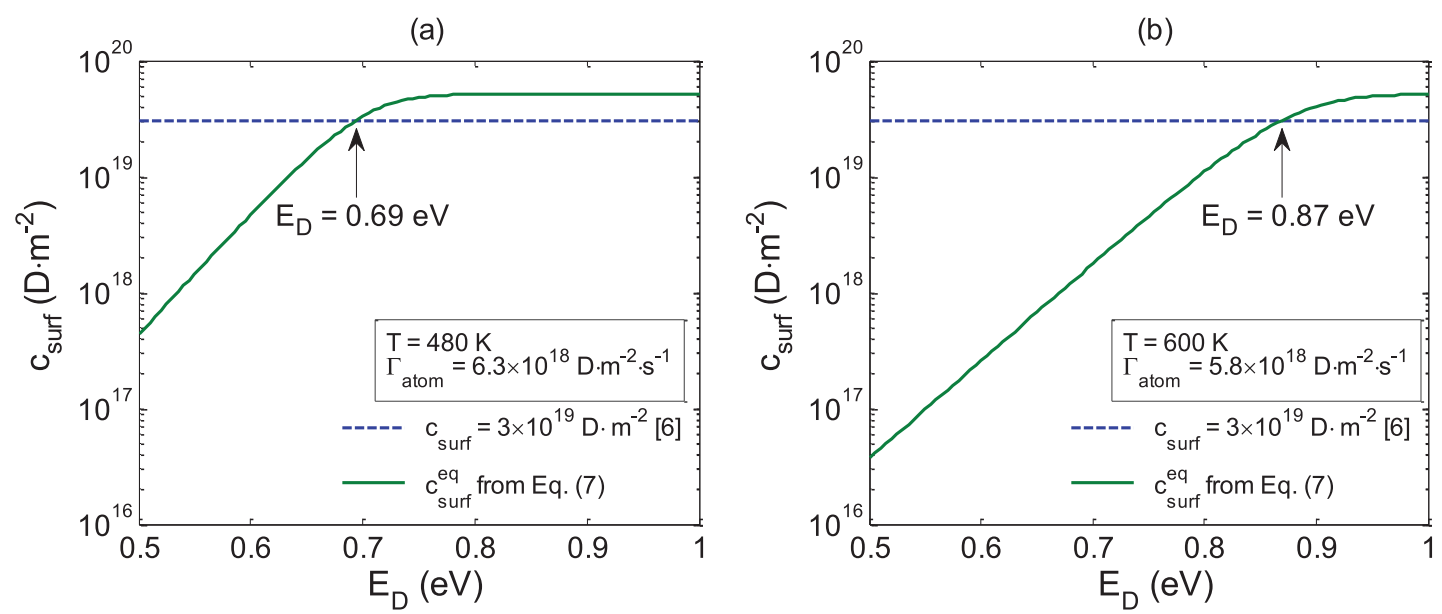

Figure 4. (a) Green solid line: evolution of $c_{\text {surf }}^{\text {eq }}$ with $E_{\mathrm{D}}$ (equation (7)) at $480 \mathrm{~K}, \Gamma_{\text {atom }}=6.3 \times 10^{18} \mathrm{D} \cdot \mathrm{m}^{-2} \cdot \mathrm{s}^{-1}$, blue dashed line: experimentally measured (ERDA) value of $c_{\text {surf }}[6]$ in the same conditions. (b) Green solid line: evolution of $c_{\text {surf }}^{\text {eq }}$ with $E_{\mathrm{D}}$ (equation (7)) at $600 \mathrm{~K}, \Gamma_{\text {atom }}=5.8 \times 10^{18} \mathrm{D} \cdot \mathrm{m}^{-2} \cdot \mathrm{s}^{-1}$, blue dashed line: value determined from experimental depth profiles [6].

(a)

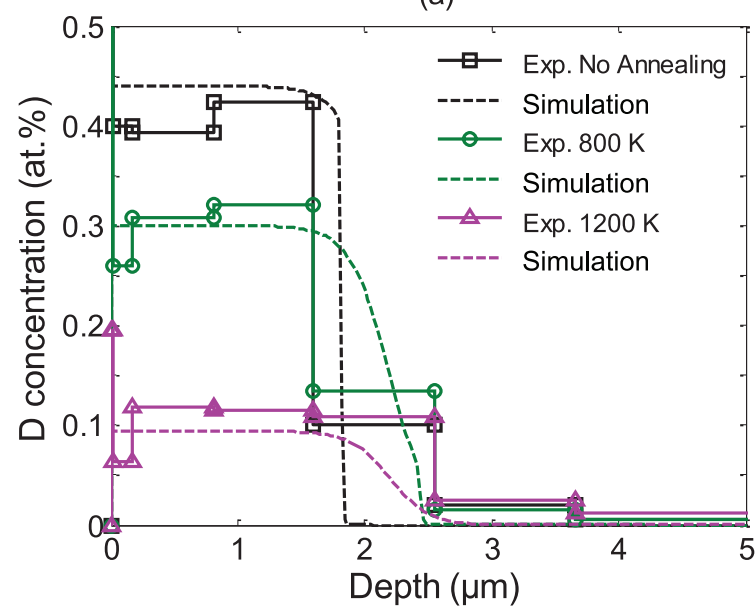

(b)

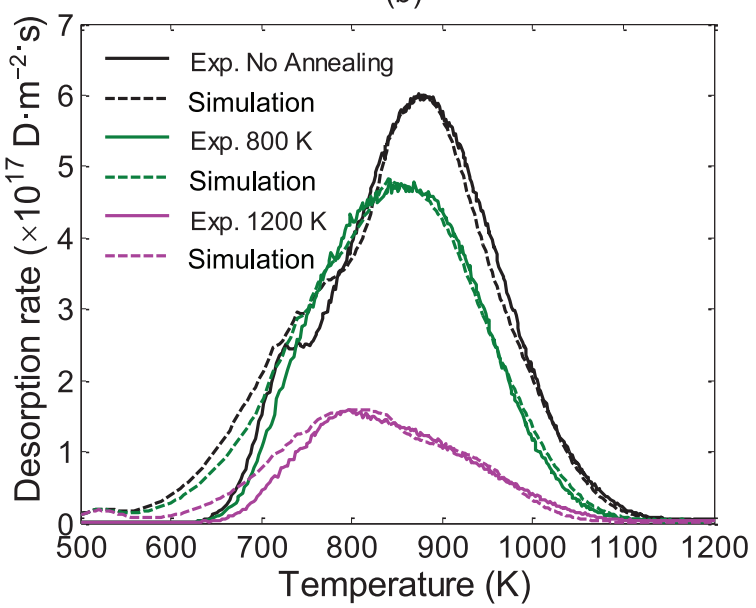

Figure 5. (a) Comparison between simulation and experimental D depth profiles obtained after a $144 \mathrm{~h} \mathrm{D}$ atom exposure on self-damaged W sample with a flux of $2.6 \times 10^{19} \mathrm{D} \cdot \mathrm{m}^{-2} \cdot \mathrm{s}^{-1}$ at $500 \mathrm{~K}$. (b) Comparison between simulated and experimental TDS spectra obtained after the same $\mathrm{D}$ atom exposure. The heating ramp is $0.25 \mathrm{~K} \mathrm{~s}^{-1}$. For the sake of clarity, only the results for un-annealed, $800 \mathrm{~K}$-annealed and $1200 \mathrm{~K}$-annealed case are shown.

exposed to $20 \mathrm{MeV} \mathrm{W}^{6+}$ ions at room temperature and at a fluence of $7.8 \times 10^{17} \mathrm{Dm}^{-2}$. The projected range of the $\mathrm{W}$ ions was calculated to be $1.5 \mu \mathrm{m}$, the thickness of the damaged layer was calculated to be $2.4 \mu \mathrm{m}$ and the irradiation dose at the damage peak was calculated in [7] to be 0.5 dpa (displacement per atom) by evaluating the vacancy.txt output from the full cascade option of the SRIM 2013 software and a displacement energy of $90 \mathrm{eV}$ [25]. After $\mathrm{W}$ damaging, the samples were annealed in vacuum for $1 \mathrm{~h}$ at different temperatures from $600 \mathrm{~K}$ and $1200 \mathrm{~K}$ except for one sample which was not annealed. Then, they were exposed at $500 \mathrm{~K}$ to a D atom beam with a thermal energy of $\sim 0.3 \mathrm{eV}$ and a flux of $2.6 \times 10^{19} \mathrm{Dm}^{-2} \mathrm{~s}^{-1}$ for $144 \mathrm{~h}$ which corresponds to a fluence of $1.3 \times 10^{25} \mathrm{Dm}^{-2}$. The samples were finally analyzed by NRA and TDS with a heating ramp of $0.25 \mathrm{~K} \mathrm{~s}^{-1}$.

First, before simulating the experimental results, energy barriers at the surface-bulk interface $\left(E_{\mathrm{A}}, E_{\mathrm{D}}\right.$ and $\left.E_{\mathrm{R}}\right)$ in vacuum were determined using the two procedures described in the previous section.
For the determination of $E_{\mathrm{D}}$, no data on the surface concentration has been reported after exposure at $500 \mathrm{~K}$ in [7]. However, in situ ERDA measurements of self-damaged W exposed to $0.3 \mathrm{eV} / \mathrm{D}$ atoms were obtained by the same group for a slightly lower temperature of $480 \mathrm{~K}$ and with a flux of $6.3 \times 10^{18} \mathrm{Dm}^{-2} \mathrm{~s}^{-1}$ [6]. These differences in temperature and flux tend to compensate each other and so experiments in $[6,7]$ should have very similar steady-state coverage. In [6], it was measured that the surface areal density in the steady state reached $3( \pm 0.5) \times 10^{19} \mathrm{Dm}^{-2}$. Using equation (7) derived from the steady-state approach presented in section 2.2 , it was determined that, in order to have this value of $c_{\text {surf }}^{\text {eq }}$, one needs $E_{\mathrm{D}}=0.69 \pm 0.02 \mathrm{eV}$ (figure $4(a)$ ). The uncertainties are evaluated by taking the extrema of the experimental values of the surface areal density.

Regarding the value of $\Delta E=E_{\mathrm{A}}-E_{\mathrm{R}}$, we use the experimental D depth profile (figure $5(a)$ ) in the nonannealed case, after $144 \mathrm{~h}$ of D atomic exposure at $500 \mathrm{~K}$ where the value of $R_{\mathrm{d}}(144 \mathrm{~h}, 500 \mathrm{~K})$ is $2 \pm 0.3 \mu \mathrm{m}$ with 
Table 2. Concentration of trap 3, trap 4 and trap 5 created by the self-damaging for the different annealing case simulated.

\begin{tabular}{llll}
\hline & Trap 3 (jogged dislocation line) & Trap 4 (dislocation loop) & Trap 5 (cavity) \\
Annealing case & $E_{\mathrm{t}, 4}=1.65 \pm 0.01 \mathrm{eV}($ at.\%) & $E_{\mathrm{t}, 5}=1.85 \pm 0.03 \mathrm{eV}($ at.\%) & $E_{\mathrm{t}, 6}=2.06 \pm 0.04 \mathrm{eV}($ at. \%) \\
\hline No annealing & 0.09 & 0.28 & 0.08 \\
$1 \mathrm{~h}$ at $600 \mathrm{~K}$ & 0.08 & 0.23 & 0.06 \\
$1 \mathrm{~h}$ at $800 \mathrm{~K}$ & 0.06 & 0.19 & 0.05 \\
$1 \mathrm{~h}$ at $1000 \mathrm{~K}$ & 0.00 & 0.15 & 0.02 \\
$1 \mathrm{~h}$ at $1200 \mathrm{~K}$ & 0.00 & 0.05 & 0.04 \\
\hline
\end{tabular}

$\sum_{i} R_{\text {trap }, i} \cdot n_{i} \approx 0.3 \pm 0.1$ at.\%: using equation (9) we get $c_{\mathrm{m}}^{\mathrm{MAX}}(500 \mathrm{~K})=1( \pm 0.6) \times 10^{-9}$ at. $\%$. The uncertainties are evaluated by taking the extrema of the value of $R_{\mathrm{d}}(144 \mathrm{~h}, 500 \mathrm{~K})$ and $\sum_{i} R_{\text {trap }, i} \cdot n_{i}$.

Using equation (5), it is finally determined that, $\Delta E=1.13 \pm 0.04 \mathrm{eV}$ at $500 \mathrm{~K}$. It is assumed that the energy barrier to go from bulk to surface $E_{\mathrm{R}}$ is roughly the migration energy of $\mathrm{H}$ in the bulk, as shown by several DFT calculations $[26,27]$, i.e. $E_{\mathrm{R}}=0.2 \mathrm{eV}$. In this case, the energy barrier required to go from surface to bulk is $E_{\mathrm{A}}=1.33 \pm 0.04 \mathrm{eV}$. The uncertainties are evaluated by taking the extrema of the determined value of $E_{\mathrm{D}}$ and $c_{\mathrm{m}}^{\mathrm{MAX}}(500 \mathrm{~K})$.

Therefore, in the simulation, the following values for the energy barriers are used: $E_{\mathrm{D}}=0.69 \mathrm{eV}, E_{\mathrm{R}}=0.2 \mathrm{eV}$ and $E_{\mathrm{A}}=1.33 \mathrm{eV}$.

Now, we turn to the determination of the bulk quantities using the D depth profile and TDS experiments. The simulation is composed of four phases, as in the experimental procedures. It begins through the simulation of $\mathrm{D}$ atomic exposure at $500 \mathrm{~K}$ for $144 \mathrm{~h}$ (the flux is $\Gamma_{\text {atom }}=2.6 \times 10^{19} \mathrm{Dm}^{-2} \mathrm{~s}^{-1}$ ). Then, the temperature is decreased within $30 \mathrm{~min}$, from $500 \mathrm{~K}$ to $300 \mathrm{~K}$. In order to simulate the storage time, the temperature is kept constant at $300 \mathrm{~K}$ for around $8 \mathrm{~h}$. Then, the temperature is increased from $300 \mathrm{~K}$ to $1300 \mathrm{~K}$ with a heating rate similar to the ramp used in the experiment: at high temperature (above $\sim 700 \mathrm{~K}$ ) the heating ramp is around $0.25 \mathrm{~K} \mathrm{~s}^{-1}$, but at the beginning of the TDS, the temperature does not evolve truly linearly.

According to our previous simulations, two HI traps exist intrinsically in undamaged PCW. They are called 'trap 1' and 'trap 2' and their detrapping energies, respectively $E_{\mathrm{t}, 1}$ and $E_{\mathrm{t}, 2}$, have been extracted from TDS simulations [9]: $E_{\mathrm{t}, 1}=0.85 \mathrm{eV}$ and $E_{\mathrm{t}, 2}=1.00 \mathrm{eV}$. In [9]. An additional extrinsic trap was found in order to account for traps induced by implantation of $\mathrm{D}$ ions. In the simulations presented in the present paper, the extrinsic traps are not necessary since D atomic exposure will not induce such traps. The total concentrations of the two intrinsic traps (i.e. the concentration in all the material, not only in the damaged zone) are around 0.01 at.\% according to NRA results obtained using a recrystallized sample from the same material at $320 \mathrm{~K}$ [28]. In the simulation, during the atomic exposure, $c_{\text {surf }}^{\mathrm{eq}} \approx 2.9 \times 10^{19} \mathrm{D} \cdot \mathrm{m}^{-2}$ and $c_{\mathrm{m}}^{\mathrm{MAX}} \approx 1 \times 10^{-9}$ at. $\%$. If the equilibrium ratio given by equation (8) is calculated for these two traps, at $500 \mathrm{~K}$ one can obtain

$$
\begin{aligned}
& R_{\text {trap }, 1}\left(500 \mathrm{~K}, c_{\mathrm{m}}^{\mathrm{MAX}}\right)=1 \times 10^{-5} \\
& R_{\text {trap }, 2}\left(500 \mathrm{~K}, c_{\mathrm{m}}^{\mathrm{MAX}}\right)=2 \times 10^{-4}
\end{aligned}
$$

Consequently, since the exposure is done at high temperature $(500 \mathrm{~K})$, these two traps will retain very few $\mathrm{D}$, as explained in [9].

Figure 5 shows the simulation results (depth profile $(a)$ and TDS spectra $(b))$ for the self-damaged PCW samples in the non-annealed case, the $800 \mathrm{~K}$-annealed case and the $1200 \mathrm{~K}$-annealed case. In order to reproduce the experimental TDS spectra from [7] (figure 5(b)), three new traps have to be introduced into the model. The detrapping energies for these three traps are $E_{\mathrm{t}, 3}=1.65 \pm 0.01 \mathrm{eV}, E_{\mathrm{t}, 4}=1.85 \pm 0.03 \mathrm{eV}$ and $E_{\mathrm{t}, 5}=2.06 \pm 0.04 \mathrm{eV}$. They will be referred to in the following as 'trap 3', 'trap 4' and 'trap 5', respectively. Experimental depth profiles show a nearly uniform concentration of D up to about $1.5 \mu \mathrm{m}$ for the non-annealed sample and up to about $2.5 \mu \mathrm{m}$ (the entire thickness of the damage layer) for the $1200 \mathrm{~K}$-annealed case. Thus, in order to reproduce the NRA depth profile (figure 5(a)), a uniform concentration for trap 3, trap 4 and trap 5 (values summarized in table 2) is considered in the damaged layer up to a depth of around $2.2 \mu \mathrm{m}$. This assumption is strengthened by the scanning transmission electron microscopy (STEM) images of the damage layer obtained on lamellae cut perpendicularly to the sample surface using the focused ion-beam techniques: these images show a homogeneous distribution of the radiation defects through the entire damaged layer [7] that decreases between $2.2 \mu \mathrm{m}$ and $2.4 \mu \mathrm{m}$. It has to be noted that non-uniform distributions were firstly tested in the simulations (based on SRIM distribution). No effect has been seen on the simulated TDS spectra, but the simulated depth profiles were not matching.

The experimental TDS spectra (figure 5(b)) exhibit a predominant $\mathrm{D}$ desorption peak at $875 \mathrm{~K}$, a desorption tail at high temperature up to $1100 \mathrm{~K}$ for all annealing cases and a smaller peak at $720 \mathrm{~K}$ for the non-annealed and $600 \mathrm{~K}$-annealed case (not shown on figure $5(b)$ ). This observation suggests the presence of at least three different detrapping energies. Note that the three desorption temperatures are more visible on the HD signal, which exhibits three well defined peaks. These three desorption temperatures explain why three detrapping energies have to be introduced. Thus, the experimental TDS spectra are well reproduced, especially the main peak at $875 \mathrm{~K}$ (detrapping from trap 4) and the high-temperature shoulder (detrapping from trap 5). Due to the presence of trap 3, a 
(a)

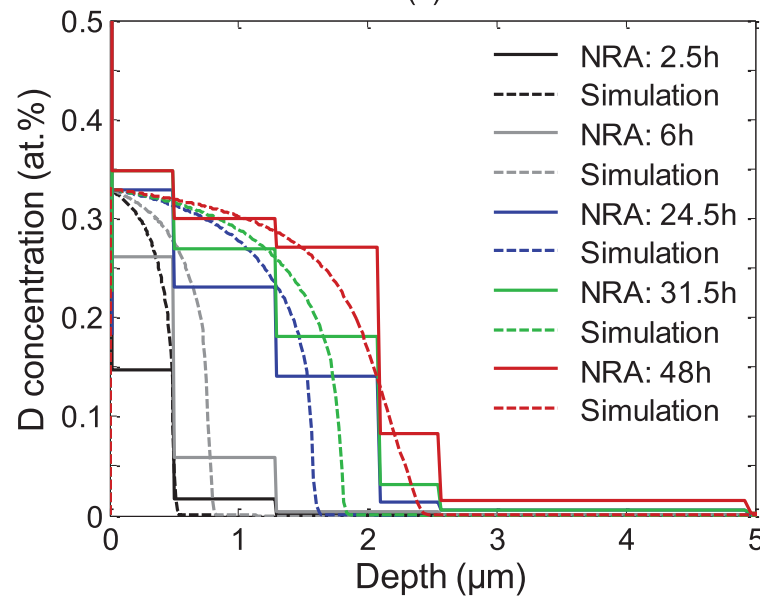

(b)

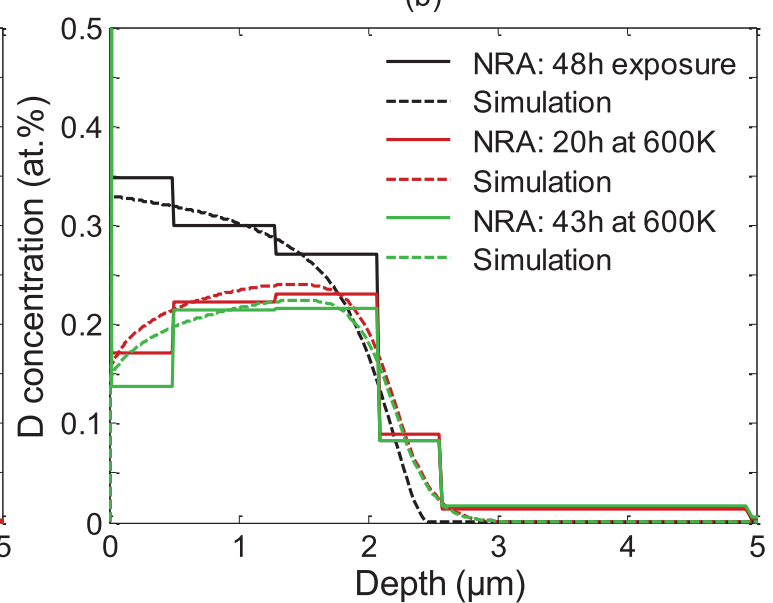

Figure 6. (a) Comparison between experimental and simulated D depth profiles during atomic exposure at $600 \mathrm{~K}$ (maximum exposure time $=48 \mathrm{~h}$ ). (b) Comparison between experimental and simulated D depth profiles during the isothermal desorption at $600 \mathrm{~K}$.

low-temperature shoulder appears that is slightly more pronounced in our simulation than experimentally. The presence of trap 3, however, is necessary in our simulations because otherwise the low-temperature shoulder (observed experimentally) would not appear in the simulations. Moreover, it will be shown in section 2.4 that trap 3 is also necessary to reproduce isothermal desorption at $600 \mathrm{~K}$.

\subsection{Simulation of $D$ atom implantation at $600 \mathrm{~K}$}

MHIMS is also used to simulate complementary experimental results published by Markelj et al [6]. In this paper, the sample preparation and the self-damaging were identical to the work of Zaloznik et al [7]. D atom exposure was performed with an average flux of $5.8 \times 10^{18} \mathrm{Dm}^{-2} \mathrm{~s}^{-1}$ at $600 \mathrm{~K}$. The NRA $\mathrm{D}$ depth profiles were recorded in situ during the exposure and the maximum $\mathrm{D}$ atom exposure time was $48 \mathrm{~h}$ which corresponds to a fluence of $10^{24} \mathrm{Dm}^{-2}$. After the D atom exposure, the sample was cooled down to room temperature and re-heated and maintained at $600 \mathrm{~K}$ to investigate isothermal outgassing.

As for the simulation of atomic exposure at $500 \mathrm{~K}$, before simulating the exposure and isothermal outgassing, the energy barriers in the vicinity of the surface were firstly estimated using the steady-state equations (5), (7) and (9).

According to the experimental D depth profile from figure $6(a)$ after $2.5 \mathrm{~h}$ of exposure at $600 \mathrm{~K}$, the part of D retained in the bulk, excluding the first point at $0 \mu \mathrm{m}$, was $\approx 5-6 \times 10^{19} \mathrm{D} \cdot \mathrm{m}^{-2}$. Furthermore, the integrated amount of $\mathrm{D}$, including the first point at $0 \mu \mathrm{m}$ that should represent the $\mathrm{D}$ on the surface, was recorded to be $\approx 8-9 \times 10^{19} \mathrm{D} \cdot \mathrm{m}^{-2}$ after $2.5 \mathrm{~h}$ of exposure at $600 \mathrm{~K}$. It could then be considered that during the atom exposure the surface concentration reaches $3( \pm 1) \times 10^{19} \mathrm{D} \cdot \mathrm{m}^{-2}$. Equation (7), derived from the steadystate approach presented in section 2.2, shows that in order to reach this value of $c_{\text {surf }}^{\text {eq }}, E_{\mathrm{D}}=0.87 \pm 0.03 \mathrm{eV}$ (figure $4(b)$ ). The uncertainties were evaluated by taking the extrema of the experimental values of the surface concentration.

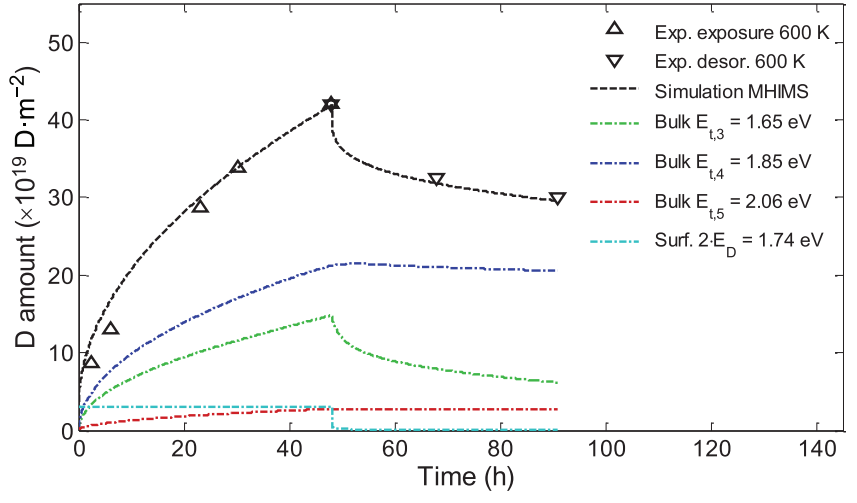

Figure 7. Comparison between simulated and experimental evolutions of the $\mathrm{D}$ total amounts with time during a $48 \mathrm{~h}$ atomic exposure at $600 \mathrm{~K}$, flux of $5.8 \times 10^{18} \mathrm{D} \cdot \mathrm{m}^{-2} \cdot \mathrm{s}^{-1}$ followed by an isothermal desorption at $600 \mathrm{~K}$ for $43 \mathrm{~h}$.

According to the experimental D depth profiles, after $48 \mathrm{~h}$ of $\mathrm{D}$ atomic exposure at $600 \mathrm{~K}$ (figure 2 in [6]) the value of $R_{\mathrm{d}}(48 \mathrm{~h}, 600 \mathrm{~K})$. can be estimated between $2 \mu \mathrm{m}$ and $2.2 \mu \mathrm{m}$ with $\Sigma_{i} R_{\text {trap }, i} \cdot n_{i} \approx 0.325$ at. $\%$. Equation (9) then gives $c_{\mathrm{m}}^{\mathrm{MAX}}=1.4( \pm 0.1) \times 10^{-9}$ at. $\%$. The uncertainties were evaluated by taking the extrema of the value of $R_{\mathrm{d}}(144 \mathrm{~h}, 500 \mathrm{~K})$ and $\sum_{i} R_{\text {trap }, i} \cdot n_{i}$.

Using equation (5), it can finally be determined that $\Delta E=1.35 \pm 0.02 \mathrm{eV}$. As for the simulation at $500 \mathrm{~K}$, using $E_{\mathrm{R}}=0.2 \mathrm{eV}$ gives $E_{\mathrm{A}}=1.55 \pm 0.02 \mathrm{eV}$. The uncertainties were evaluated by taking the extrema of the determined value of $E_{\mathrm{D}}$ and $c_{\mathrm{m}}^{\mathrm{MAX}}(600 \mathrm{~K})$.

In the simulation, the value used were $E_{\mathrm{D}}=0.87 \mathrm{eV}$, $E_{\mathrm{R}}=0.2 \mathrm{eV}$ and $E_{\mathrm{A}}=1.55 \mathrm{eV}$. They are different from the ones used at $500 \mathrm{~K}$ and this behavior will be addressed in the discussion section.

The simulation of the experiments presented in [6] is composed of two phases: the atomic exposure at $600 \mathrm{~K}$ and the isothermal desorption at $600 \mathrm{~K}$. In order to simplify the simulation, the cooling and the re-heating phases are not simulated. As shown by the steady-state analysis, in the simulation, 
during the atomic exposure $c_{\text {surf }} \approx 3 \times 10^{19} \mathrm{D} \cdot \mathrm{m}^{-2}$ and $c_{\mathrm{m}}^{\mathrm{MAX}} \approx 1.3 \times 10^{-9}$ at. $\%$. Figure 6 shows the comparison between the $\mathrm{D}$ depth profiles during the atom exposure (figure $6(a)$ ) and during the isothermal desorption (figure $6(b)$ ). Figure 7 shows the evolution of the D retention (in the bulk and at the surface) for both the experiment and the simulation. The simulation is able to reproduce (with good agreement) the evolution of the retention with time during the atom exposure and during the isothermal desorption shown in [6]. The same traps used in section 2.3 are used here:

- The intrinsic traps with the same trap concentrations as in section 2.3: the detrapping energies are $E_{\mathrm{t}, 1}=0.85 \mathrm{eV}$ and $E_{\mathrm{t}, 2}=1.00 \mathrm{eV}$. Due to their low detrapping energies, the retention in those traps does not influence the results considering that the exposure temperature is $600 \mathrm{~K}$.

- The three new traps used in section 2.3 to reproduce the experimental TDS spectra. The detrapping energies are: $E_{\mathrm{t}, 4}=1.65 \mathrm{eV}, E_{\mathrm{t}, 5}=1.85 \mathrm{eV}$ and $E_{\mathrm{t}, 6}=2.06 \mathrm{eV}$.

To reproduce the experimental D depth profiles during the atom exposure and the isothermal desorption (figure 6), the traps in the damaged layer are distributed as explained previously: constant from the surface to $2.2 \mu \mathrm{m}$ and decreasing between $2.2 \mu \mathrm{m}$ and $2.4 \mu \mathrm{m}$. In the damaged layer, the trap concentration is $n_{3}=0.19$ at. $\%, n_{4}=0.16$ at. $\%$ and $n_{5}=0.02$ at. $\%$.

Concerning the evolution of the $\mathrm{D}$ amount during exposure and isothermal desorption (figure 7), it is especially interesting to see that, during the isothermal desorption, the $\mathrm{D}$ release is initially due to the rapid outgassing from the surface (in the first minutes). Then, D is released mainly from trap 3 and a small fraction from trap 4 and no desorption is observed from trap 5 since the detrapping energy is too high to allow it. Concerning the $\mathrm{D}$ depth profile (figure 6) during the atomic exposure, in both experimental and simulation results, the D total concentration (mobile + trapped) propagates in the bulk as the fluence (exposure time) increases. This migration can be understood as diffusion hindered by the presence of trap 3 , trap 4 and trap 5 in the damaged layer. The corresponding effective diffusion coefficient can be roughly calculated as $D_{\text {eff }}=\frac{L_{\text {mig }}^{2}}{t_{\text {exposure }}}$ with $L_{\text {mig }}$ the migration length observed in the simulation (figure $6(a)$ ) for the exposure time $t_{\text {exposure. From }}$ the simulation results, $D_{\text {eff }} \approx 10^{-17} \mathrm{~m}^{2} \cdot \mathrm{s}^{-1}$. This effective diffusion coefficient is far lower than the diffusion coefficient in the bulk that we used (at $600 \mathrm{~K} D_{\mathrm{H}}(T)=3 \times 10^{-9} \mathrm{~m}^{2} \cdot \mathrm{s}^{-1}$ ). This reduced effective diffusion coefficient is due to the presence of traps with high detrapping energies and high trap concentrations. Deeper in the bulk, i.e. outside of the damaged layer, the effective coefficient will be higher than in the damaged layer since the only traps present are the intrinsic traps with lower detrapping energies and lower trap concentrations. During the isothermal desorption, the maximum concentration decreases from around 0.3 at. $\%$ to around 0.2 at. $\%$ and a shift of the maximum concentration from the surface to around $1.5 \mu \mathrm{m}$ is observed in the simulation as well as in the experiments (figure $6(b)$ ). It is also observed that the concentration just below the surface drops to around 0.15 at.\%, which agrees with the experimental observations.

\section{Discussion}

\subsection{Surface-energy barriers}

In this paper, a model to describe $\mathrm{D}$ atom interaction with the surface has been proposed. The surface is commonly described using a recombination coefficient $K_{\mathrm{r}}(T)\left(\mathrm{m}^{4} \cdot \mathrm{s}^{-1}\right)$, as in TMAP7 [29], assuming a local equilibrium between the bulk and the surface. This description implies that, in the steady state, the following relation can be written [14]: $s \cdot \Gamma_{\text {inc }}=2 \cdot K_{\mathrm{r}}(T) \cdot\left(c_{\mathrm{m}}^{\mathrm{eq}}\right)^{2}$ with $\Gamma_{\text {inc }}\left(\mathrm{m}^{-2} \cdot \mathrm{s}^{-1}\right)$ the incident flux of particles (molecules or atoms) and $s$ (dimensionless) the sticking probability of these particles. Thus, this description is valid if the concentration of particles in the bulk is proportional to the square root of the incident flux, which is the case for molecular exposure as shown by Pick et al [14]. Indeed, in Pick et al's model, which is similar to the one described here, but without the direct abstraction, the concentration of particles in the bulk can take the following form in the steady state: $c_{\mathrm{m}}^{\mathrm{eq}}=\frac{\nu_{\mathrm{sb}}(T)}{\nu_{\mathrm{bs}}(T)} \cdot\left(\frac{\Gamma_{\mathrm{inc}} \cdot s}{\nu_{\mathrm{des}}(T)}\right)^{\frac{1}{2}}$. From this formula, Pick et al expressed the recombination coefficient as $K_{\mathrm{r}}(T)=\frac{\nu_{\mathrm{bs}}^{2}(T) \cdot \nu_{\mathrm{des}}(T)}{\nu_{\mathrm{sb}}^{2}(T)}$ [14] which for our cases gives: $K_{\mathrm{r}}(T)=6 \times 10^{-27} \cdot \mathrm{e}^{-\frac{0.88 \mathrm{eV}-0.96 \mathrm{eV}}{k_{\mathrm{B}} \cdot \mathrm{T}}}$ $\left(\mathrm{m}^{4} \cdot \mathrm{s}^{-1}\right)$.

Nevertheless, in the case of an atomic exposure with the present model that includes the direct abstraction process, the concentration of particles in the bulk in the steady state takes a more complex form. Introducing equation (7) into equation (5), the concentration of particles in the bulk is no longer directly proportional to the square root of the incident flux, meaning that the description of the surface with a recombination coefficient is not valid. In addition, it has already been pointed out [30-32] that the most important issue related to the recombination coefficient is the large scattering of the different values used in the literature. In this respect, with the present study, another way to describe the surface has been proposed here that does not involve any recombination coefficient. This model introduces three new free parameters: the desorption energy $E_{\mathrm{D}}$, the resurfacing energy $E_{\mathrm{R}}$ and the energy barrier for absorption $E_{\mathrm{A}}$, which have to be determined. The NRA and TDS spectra give coupled information on the bulk and surface properties. Thus, the simulations of such experiments can only be an indirect way to determine these three new parameters. In order to tackle this issue, a procedure was proposed in section 2.2, based on a steady-state analysis as well as a simplified model for the bulk diffusion/trapping of D initially proposed by Schmid et al [22] in the case of ion implantations and extended here in the case of atom exposure (figure 6). This procedure allows us to determine the surfaceenergy barriers independently of bulk energy barriers.

Desorption energies per D atom determined in the present work, using the approach presented in section 2.2, are $E_{\mathrm{D}}(500 \mathrm{~K})=0.69 \pm 0.02 \mathrm{eV}$ and $E_{\mathrm{D}}(600 \mathrm{~K})=0.87 \pm$ $0.03 \mathrm{eV}$. These two values are in agreement with experimental $[19,33,34]$ and DFT $[21,26,35,36]$ values for $E_{\mathrm{D}}$ that range between $0.50 \mathrm{eV}$ and $0.90 \mathrm{eV}$. Naturally, this leads one to wonder how $E_{\mathrm{D}}$ could change with temperature upon D atom exposure. In line with Tamm and Schmidt's interpretation [19], 
Markelj et al [20] linked this type of behavior with the presence of several binding states with different $E_{\mathrm{D}}$ values, where the lowest $E_{\mathrm{D}}$ states were increasingly populated as the surface temperature decreases upon D exposure. Another interpretation can be proposed following the work of Alnot et al [33] and Nahm and Gomer [37]. In these studies, it was found that $E_{\mathrm{D}}$ was decreasing by $0.1-0.3 \mathrm{eV}$ when the increasing hydrogen surface coverage crossed a threshold of about 0.3-0.4, most likely due to adsorbate-adsorbate repulsive interaction. The coverages $\theta=\frac{c_{\text {surf }}}{n_{\text {surf }}}$ of the present simulation analysis are $\theta(500 \mathrm{~K})=0.20-0.37$ and $\theta(600 \mathrm{~K})=0.16-0.42$. The fact that we found $E_{\mathrm{D}}$ decreases by $0.18 \pm 0.05 \mathrm{eV}$ when the surface temperature decreases (i.e. increased surface coverage at a constant flux) is consistent with both interpretations.

By postulating that the resurfacing energy $E_{\mathrm{R}}$ is the same as the diffusion energy, i.e. $0.2 \mathrm{eV}$, the present work found energy barriers for absorption of D from surface to bulk of $E_{\mathrm{A}}(500 \mathrm{~K})=1.33 \mathrm{eV}$ and $E_{\mathrm{A}}(600 \mathrm{~K})=1.55 \mathrm{eV}$ using the approach presented in section 2.2. These values are in agreement with the recent experiments of 't Hoen et al [10] which argued that the insertion of $5 \mathrm{eV} / \mathrm{D}$ ions is limited by surface processes, and obtained an absorption energy comprised of between 1 and $2 \mathrm{eV}$, once experimental uncertainties are taken into account. However, our $E_{\mathrm{A}}$ values are lower compared to the ones calculated by DFT. which are comprised of between $1.7 \mathrm{eV}$ and $2 \mathrm{eV}[21,26,27,35]$. One should note that DFT studies tend to disagree regarding the exact shape of the minimum energy path for hydrogen insertion into the bulk through the W(100) face, with $E_{\mathrm{R}}>E_{\mathrm{diff}}$ in some cases and $E_{\mathrm{R}}<E_{\mathrm{diff}}$ in other cases. It is even found that $E_{\mathrm{R}} \approx 0 \mathrm{eV}$ for the W(110) case. Therefore, for a polycrystalline sample, it is difficult to determine the value of $E_{\mathrm{R}}$, and thus of $E_{\mathrm{A}}$, with good accuracy. Further experimental and theoretical studies are needed in order to clarify the exact energy barriers for hydrogen transition from the surface to the bulk and back.

The solution energy $E_{\mathrm{S}}=E_{\mathrm{A}}-E_{\mathrm{D}}+\frac{1}{2} \cdot E_{\mathrm{diss}}-E_{\mathrm{R}}$ (figure 1) was measured by Frauenfelder [38] and found to be equal to $1.04 \mathrm{eV}$ in the $\mathrm{HI} / \mathrm{W}$ system. Value of $E_{\text {diss }}$ are available in the literature for single crystals. Following the first DFT study of White et al [39] into $\mathrm{H}_{2}$ dissociation on W(100), Busnengo and Martinez [40] constructed sixdimension potential energy surfaces (PESs) for $\mathrm{H}_{2}$ dissociative adsorption on $\mathrm{W}(100)$ and $\mathrm{W}(110)$. They ran quasi-classical MD simulations on these PESs in order to reproduce the molecular-beam results from Berger et al [41] and Butler et al [42] with fairly good agreement. This positive result inspires confidence in their DFT results used for PESs construction, which show that a reasonable portion of configuration space is barrierless for both $\mathrm{W}$ crystal cuts. Therefore, we chose for the polycrystalline samples simulated in the present work to set $E_{\text {diss }}=0.0 \mathrm{eV}$. Using this value, we obtained a solution energy $E_{\mathrm{S}}=0.44 \mathrm{eV}$ at $500 \mathrm{~K}$ and $E_{\mathrm{S}}=0.48 \mathrm{eV}$ at $600 \mathrm{~K}$, which is significantly lower than the value of $1.04 \mathrm{eV}$ obtained by Frauenfelder [38].

The discrepancy could come from the difference in sample preparation in the works of Frauenfelder and in the work of Markelj et al [6] and Zaloznik et al [7]. In the first one, the sample was annealed at $2400 \mathrm{~K}$ for $10 \mathrm{~h}$ in vacuum and then at $2400 \mathrm{~K}$ for $10 \mathrm{~h}$ in $\mathrm{H}_{2}$ atmosphere (600 Torr), while in the second two, samples were annealed for $2 \mathrm{~min}$ at $2000 \mathrm{~K}$. In addition, while in the case of Frauenfelder the samples were annealed in vacuum before $\mathrm{H}$ exposure, they were exposed to air between NRA and TDS analysis in the case of Markelj et al and Zaloznik et al. It is well known that W oxide needs a temperature of $2400 \mathrm{~K}$ to for annealing [43]. Thus, differences in surface oxide coverage may be responsible for the different values of solution energy determined from Markelj and Zaloznik's experiments and from Frauenfelder's experiments. Other explanations could involve variation in $\mathrm{W}$ crystal purity and subsequent surface segregation of contaminants.

The discrepancy with Frauenfelder results could also be explained by the presence of grain boundaries (GBs) in the material. Indeed, using a thermodynamic model to describe the GB effect on hydrogen solubility, Oda [44] showed that the GBs decrease (respectively increase) the value of the solution energy (respectively the solubility) significantly below $1000 \mathrm{~K}$. This effect was not seen in the experiments of Frauenfelder where the W samples were loaded and desorbed above $1100 \mathrm{~K}$. On the other hand, in the experiments simulated in this paper, with temperature of $500 \mathrm{~K}$ and $600 \mathrm{~K}$, the GB effect may change the apparent solubility and solution energy obtained.

Finally, another explanation could invoke the additional potential energy of $\mathrm{D}$ atoms arriving on the surface compared to $\mathrm{D}_{2}$ molecules. Thanks to the transformation of a part of this potential energy into kinetic energy of the incident atoms, some of them may reach the sub-surface layer more easily than D coming from molecules. This transformation of energy involves dynamic processes that may be taken into account in our kinetic model by reducing the energy barrier $E_{\mathrm{A}}$. Thus, it would reduce the solution energy obtained from the energy barriers $E_{\mathrm{A}}, E_{\mathrm{R}}$ and $E_{\mathrm{D}}$. Nevertheless, it has to be pointed out that the penetration probability of low energetic D atoms has been investigated by Maya [11] with MD simulations using the $\mathrm{H}-\mathrm{W}$ potentials of $\mathrm{Li}$ et al [45] and Juslin et al [18]. Maya showed that, for incident energies below $1 \mathrm{eV} / \mathrm{D}$, the fraction of stuck atoms reaching the first sub-surface layer is below $5 \%$ for the $\mathrm{H}-\mathrm{W}$ potential of Juslin et al and $0 \%$ for the potential of Li et al (see figure 8 in [11]). Galparsoro et al [46] also conducted MD simulations and found very similar results showing that, for incident energy below $0.5 \mathrm{eV} / \mathrm{H}$, there was no absorption of $\mathrm{H}$ below the surface after $1 \mathrm{ps}$ of simulation. This means that the excess of potential energy is somehow dissipated through different channels. Experimentally, Bünermann et al [47] observed a large loss of translational energy of $2.76 \mathrm{eV} / \mathrm{H}$ incident atoms impinging on a clean gold surface. To investigate this loss of energy, MD simulations self-consistently treating the mechanical energy transfers to the $\mathrm{Au}$ lattice motion and electronic excitations have been used. Bünermann et al's simulations showed that the energy is lost through electron-hole pair excitation. Such dissipation processes were also observed by Galparsoro et al [48] by running quasi-classical MD simulations of an $\mathrm{H}$ atom impinging a (100) and (1 1 10$) \mathrm{W}$ surface using a generalized Langevinoscillator scheme to take into account the coupling to phonons 


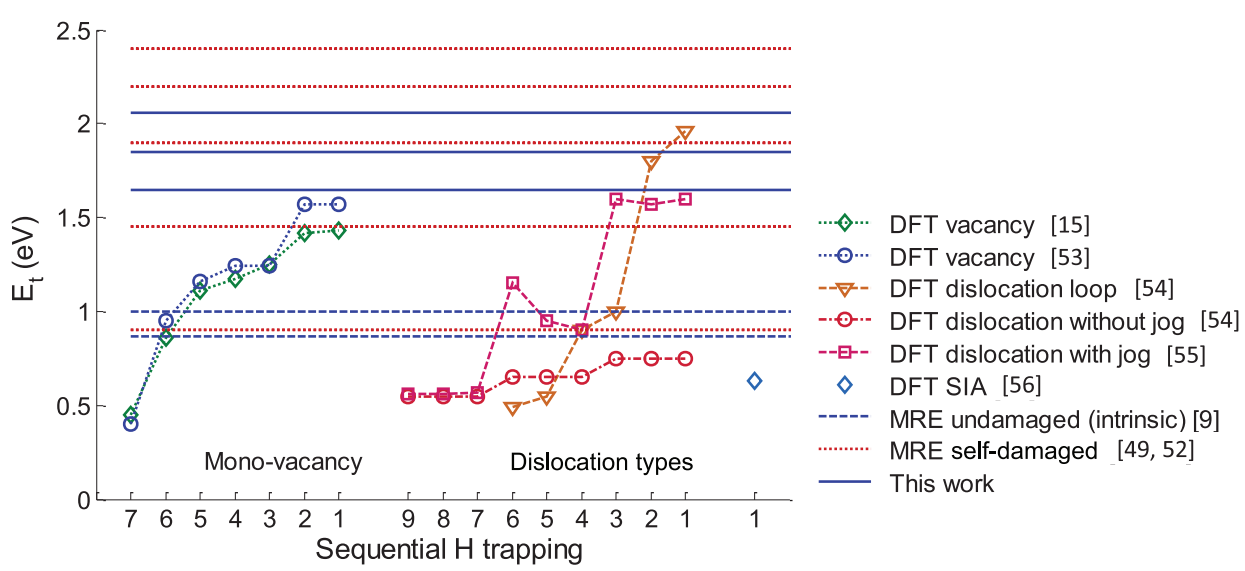

Figure 8. Evolution of detrapping energies calculated by DFT with the number of $\mathrm{H}$ trapped inside different defects. For the $\mathrm{H}$ trapped in mono-vacancy, DFT data from Fernandez et al [15] and from You et al [53]. For H trapped by dislocations, DFT data from Terentyev et al [55] for dislocation line without and with jog and DFT data from Xiao et al [54] for dislocation loop. For H trapped by SIAs, DFT data from Heinola et al [56]. The detrapping energies are calculated by adding the migration energies calculated by DFT $(0.2 \mathrm{eV})$ to the binding energies calculated by DFT for these defects. In this figure we also report the detrapping energies of intrinsic traps previously determined in [9], and detrapping energies of the self-damaged-induced trap determined in the MRE simulation from Ogorodnikova et al [49, 52] and in the present study. Detrapping energies from other MRE models are not presented on this plot for the sake of clarity.

and the local-density friction approximation to render the electron-hole pair excitations. Galparsoro et al's simulations showed that both processes can dissipate the kinetic energy of the incident $\mathrm{H}$ atom. In the case of the $\mathrm{H}$ atoms on a clean $\mathrm{W}$ surface, the dissipation by electron-hole excitation seems to be the main dissipation process although, as explained earlier, the surface of the materials used in the experiments simulated in this paper may not be clean $\mathrm{W}$ surfaces, which may change the relative efficiency of the different dissipation processes.

\subsection{Detrapping energies in the bulk}

In the present work, the simulation shows that, at $500 \mathrm{~K}$ and at $600 \mathrm{~K}$, self-damaged $\mathrm{W}$ contains three more type of traps than undamaged $\mathrm{W}$. The associated detrapping energies are $E_{\mathrm{t}, 3}=1.65 \mathrm{eV}, E_{\mathrm{t}, 4}=1.85 \mathrm{eV}$ and $E_{\mathrm{t}, 5}=2.06 \mathrm{eV}$. Previous simulations of retention/desorption from self-damaged $\mathrm{W}$ samples [5, 49, 50] and neutron-irradiated samples [51] exhibit similar trends:

- Gasparyan et al [5] reported detrapping energies between 1.7 and $2.0 \mathrm{eV}$.

- Ogorodnikova et al $[17,49,52]$ reported detrapping energies of $0.9 \mathrm{eV}, 1.45 \mathrm{eV}, 1.85-1.9 \mathrm{eV}, 2.2 \mathrm{eV}$ and $2.4 \mathrm{eV}$.

- 't Hoen et al [50] reported detrapping energies of $1.2 \mathrm{eV}$, $1.4 \mathrm{eV}, 1.85 \mathrm{eV}$ and $2.05 \mathrm{eV}$.

- Shimada et al [51] reported values of $0.9 \mathrm{eV}, 1.5 \mathrm{eV}$, $1.75 \mathrm{eV}$ and $2.0 \mathrm{eV}$.

In order to understand the nature of the traps created by neutrons or self-irradiations, the detrapping energies determined in this work are compared with detrapping energies calculated by DFT for $\mathrm{H}$ trapped in mono-vacancies [15, 53], dislocation loops [54] and dislocations with and without jog [55] (figure 8). Since the samples were irradiated with W ions, self-interstitial atoms (SIA) are also plausible traps for His; however, the corresponding detrapping energy is less than $0.7 \mathrm{eV}$ [56], which means that the SIAs possibly created during W self-irradiation will not trap the HIs atoms efficiently at $500 \mathrm{~K}$ or $600 \mathrm{~K}$.

3.2.1. Trapping in mono-vacancies? The first possible type of defect created by self-irradiation is a mono-vacancy. It has been shown by DFT calculations $[15,53]$ that the detrapping energy of $\mathrm{H}$ bound with a mono-vacancy is $1.2 \mathrm{eV}-1.1 \mathrm{eV}$ if the mono-vacancy is filled with $3-5 \mathrm{H}$ and it becomes $1.5-1.3 \mathrm{eV}$ if the mono-vacancy is filled with 1-2 $\mathrm{H}$, as shown figure 8 . These DFT values are consistent with the reported detrapping energies of $1.45 \mathrm{eV}$ by Ogorodnikova et al [49, 52], of $1.2 \mathrm{eV}$ and $1.4 \mathrm{eV}$ reported by 't Hoen et al [50] and of $1.5 \mathrm{eV}$ by Shimada et al [51]. These authors linked this range of detrapping energies with TDS peaks in the $450-650 \mathrm{~K}$ range following $\mathrm{HI}$ ion/atom exposure in the 300$525 \mathrm{~K}$ range. In the experiments of Zaloznik et al [7], simulated in the present study, $\mathrm{HI}$ atom exposure were performed at a sample temperature of $500 \mathrm{~K}$, but the absence of a TDS peak in the $450-650 \mathrm{~K}$ range leads us to conclude that there is an absence of extrinsic traps below $1.65 \mathrm{eV}$. To rationalize this apparent discrepancy between various experiments, one has to consider the temperature stability of mono-vacancies. Using positron annihilation spectroscopy (PAS), Debelle et al [57] have shown that mono-vacancies are stable following a one-hour annealing up to $523 \mathrm{~K}$. However, between $523 \mathrm{~K}$ and $573 \mathrm{~K}$, the mobility of mono-vacancies increases and agglomeration starts generating cavities, i.e. clusters of vacancies with higher detrapping energies (see section 3.2.3). We used a thermally activated first-order kinetic process [12] with a $10^{13} \mathrm{~s}^{-1}$ pre-exponential factor to analyze the Debelle et al results and found that a $1 \mathrm{~h}$ time constant for vacancy mobility in the $523 \mathrm{~K}-573 \mathrm{~K}$ range corresponds to a vacancy migration energy in the $1.72-1.88 \mathrm{eV}$ range. This analysis agrees well with vacancy-migration energy measurements in $\mathrm{W}$ of $1.7-1.8 \mathrm{eV}$ [58]. Using this simple kinetic model, we estimated that in the experimental conditions of " $t$ Hoen et al (HI exposure at $525 \mathrm{~K}$ ), the typical time constant for vacancy 
migration would be on the $1-3 \mathrm{~h}$ range, i.e. much longer than the $80 \mathrm{~s}$ duration used for their HI exposure. A shorter duration (by several orders of magnitude) for HI exposure as compared to the vacancy-migration time constant are also found for the Ogorodnikova et al and Shimada et al experiments. On the other hand, in the experimental conditions of Zaloznik et al ( $\mathrm{HI}$ exposure at $500 \mathrm{~K})$, an estimated $6-247 \mathrm{~h}$ range for vacancy migration should allow a significant migration and agglomeration of mono-vacancies during the $144 \mathrm{~h}$ HI exposure leading to the disappearance of the mono-vacancy signature in their TDS experimental spectra. Therefore, we conclude that the absence of mono-vacancy-like detrapping energies in our MHIMS simulations of Zaloznik and Markelj experiments is consistent with an efficient mono-vacancy migration and agglomeration during their long $\mathrm{HI}$ exposure at $500 \mathrm{~K}$ and $600 \mathrm{~K}$.

3.2.2. Trapping in dislocations. The nature of some of the traps created by neutron or heavy-ion irradiations can be deduced from STEM [7, 59] or PAS [50]. Indeed, in STEM images, dislocation lines, loops and cavities are observed and PAS analysis shows the presence of cavities.

Using DFT, Terentyev et al [55] calculated the binding energy of $\mathrm{H}$ with jogged dislocations to be $1.4 \mathrm{eV}$ for $1-3 \mathrm{HIs}$ trapped and $0.7 \mathrm{eV}$ for $4-5 \mathrm{HIs}$ trapped. Using the migration energy of $\mathrm{H}$ in $\mathrm{W}$ reported by DFT works [15, 60], i.e. $0.2 \mathrm{eV}$, the detrapping energy of $\mathrm{H}$ bound to jogged dislocation lines is $1.6 \mathrm{eV}$ for $1-3 \mathrm{HIs}$ trapped and $0.9 \mathrm{eV}$ for 4-5 HIs trapped (figure 8). According to this calculation, the detrapping of $0.9 \mathrm{eV}$ reported by Ogorodnikova et al $[49,52]$ could correspond to the trapping in jogged dislocations (seen by STEM) filled with 4-5 HIs. On the other hand, the trap identified as trap 3 in the Zaloznik and Markelj experiments in the present study could be related to D trapping in jogged dislocation lines filled with 1-3 HIs (figure 8).

Using DFT, Xiao et al [54] calculated the binding energy of $\mathrm{H}$ with a dislocation loop created by removing one layer in the 16-layer supercell in order to get a stacking defect. The binding energy of $\mathrm{H}$ with such a defect is between 1.6 and $1.8 \mathrm{eV}$ for $1-2 \mathrm{HI}$ trapped and falls down to $0.8 \mathrm{eV}$ for a third $\mathrm{HI}$ trapped. Using the migration energy of $\mathrm{H}$ in $\mathrm{W}$ once more, reported by DFT works $[15,60](0.2 \mathrm{eV})$, we obtain detrapping energies from such a dislocation loop of $1.8-2.0 \mathrm{eV}$ and $1.0 \mathrm{eV}$, depending on the HI filling level (figure 8). Trap 4 identified in the present simulations of Zaloznik and Markelj experiments could thus correspond to dislocation loops with a low filling level, i.e. with 1-2 HIs.

To test the assignment proposed above, we looked at the distribution and evolution of these dislocations-type traps for different annealing temperatures and compared this to the evolution of defects seen by STEM images [7]. In order to do this comparison, the trap distributions obtained for each trap in the damaged layer are integrated between 0 and $2.4 \mu \mathrm{m}$ (figure 9). Figure 9 and table 2 show that, in the simulations, the dominant trap is trap 4, which we attributed to dislocation loops. Experimental STEM images of the damaged layer show that the density of dislocation loops is higher than the density of dislocation lines [7], even though it is not

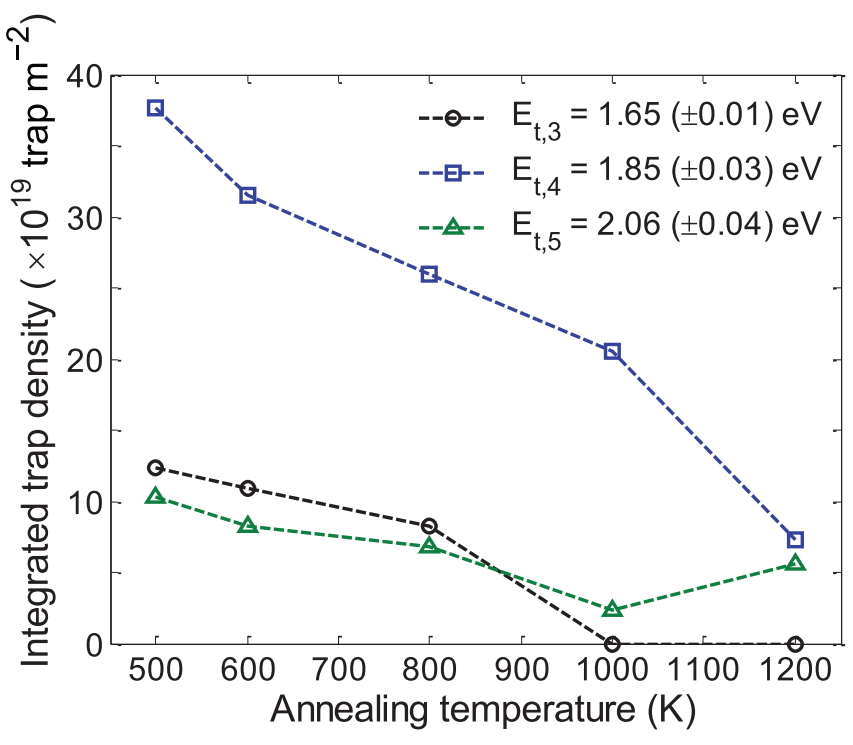

Figure 9. Integrated trap amount between 0 and $2.4 \mu \mathrm{m}$ as function of the annealing temperature for the simulation of $\mathrm{D}$ atom exposure at $500 \mathrm{~K}$. The point at $500 \mathrm{~K}$ corresponds to the unannealed case.

in the same ratio as we determined in figure 9. Furthermore, upon annealing up to $1200 \mathrm{~K}$, the total amount of dislocations (trap 4 and 5) decreases by $70 \%$ in the simulations, similarly to the experimental analysis of STEM images [7], which showed a decrease of $66 \%$ in the dislocation density. Given the quantitative agreement between DFT calculations and our simulations, determination of detrapping energy as well as the at-least qualitative reproduction of their kinetic behavior with experimental annealing observations, we believe that our assignment of trap 3 and 4 to jogged dislocation lines and dislocation loops, respectively, is well supported. This assignment is indicated in table 2 .

3.2.3. Trapping in cavities. To the best of our knowledge, no DFT calculations have been performed so far to tackle the question of HI adsorption on a vacancy-cluster, also known as a 'tungsten cavity'. Gorodetsky et al [61] suggested that to calculate the binding energy of HIs in a vacancy cluster, one can consider HI on a free surface as a good proxy. As a consequence, we estimate the detrapping energy from cavities $E_{\mathrm{B}}^{\mathrm{HV}_{n}}$ using the absorption energy of $\mathrm{HI}$ from the surface, i.e. $E_{\mathrm{B}}^{\mathrm{HV}_{n}}=E_{\mathrm{A}}$ (figure 1). We will make a comparison of the detrapping energy of the remaining trap $5\left(E_{\mathrm{t}, 5}\right)$ from our simulations with the activation energies required to go from the surface to the bulk, calculated by DFT from the literature [21, 26, 27, 35]. From our simulations we obtained $E_{\mathrm{t}, 5}=2.06 \pm 0.04 \mathrm{eV}$, which compares favorably with the upper range of DFT values found between $1.7 \mathrm{eV}$ and $2.0 \mathrm{eV}$. Therefore, we propose that the higher detrapping energy $E_{\mathrm{t}, 5}$ extracted from the Zaloznik and Markelj experiments, may be related to cavities. One should note that the increase of the density of trap 5 between 1000 and $1200 \mathrm{~K}$, seen in our simulations (figure 9), is consistent with the STEM observations of Watanabe et al [59] on $\mathrm{MeV}-\mathrm{Cu}$-damaged W. However, care has to be taken here because the amount of defects and their evolutions with annealing temperature in the case of $\mathrm{MeV}$-Cu-irradiated $\mathrm{W}$ 
samples may be different compared to self-damaged W samples. For instance, a $\mathrm{Cu}$ atom in an interstitial position can trap an HI with a binding energy higher than $0.5 \mathrm{eV}$ [62], which would correspond to a detrapping energy higher than $0.7 \mathrm{eV}$ : such a trap can retain HIs only below around $300 \mathrm{~K}$. In order to be conclusive in relation to the presence of cavities in selfdamaged $\mathrm{W}$, further experimental and theoretical studies are needed to characterize the energetic and the kinetic stability of $\mathrm{W}$ vacancy clusters in self-damaged $\mathrm{W}$.

It must also be noted that the detrapping energy of $2.06 \mathrm{eV}$ could also be related to the desorption of $\mathrm{D}$ from the $\mathrm{D}-\mathrm{C}$ bond in the case where the sample surface would be contaminated with an amorphous hydrocarbon layer. Indeed, it is known in the literature that an amorphous carbon layer retained HIs at a high temperature $[63,64]$ with high detrapping energies that can be around $2.0-2.4 \mathrm{eV}$. The presence of such a layer on the samples used in the experiments simulated in this paper has not yet been demonstrated, but could be an alternative explanation for trap 5.

\section{Conclusions}

Simulations of $\sim 0.3 \mathrm{eV}$ D atom exposure in $\mathrm{W}$ self-damaged samples have been carried out for two exposure temperatures $(500 \mathrm{~K}$ and $600 \mathrm{~K})$ using an upgraded version of MHIMS, which is based on a classical macroscopic rate-equation model that couples bulk diffusion described by Fick's law and trapping at (and release from) bulk defects described by transition state theory. Since $0.3 \mathrm{eV}$ is a low kinetic energy, we implemented a description of the impinging atom that would first be adsorbed on the surface, and a kinetic model describing the interactions between HIs and W on the surface has been proposed. This model takes into account the HIs sticking on the surface, the HI molecule desorption from the surface, the abstraction by the incoming atom flux, the absorption from the surface to the bulk and the resurfacing from the bulk to the surface.

The energy barriers at the surface were first determined using steady-state formulae and experimental observations. Considering a pre-exponential factor of $10^{13} \mathrm{~s}^{-1}$, it was found that at $500 \mathrm{~K}$ the desorption energy is $E_{\mathrm{D}}=0.69 \pm 0.02 \mathrm{eV}$ and the absorption energy is $E_{\mathrm{A}}=1.33 \pm 0.04 \mathrm{eV}$, with the resurfacing energy $E_{\mathrm{R}}$ to go from the bulk to the surface $E_{\mathrm{R}}=0.2 \mathrm{eV}$. At $600 \mathrm{~K}$, these energies change and become $E_{\mathrm{D}}=0.87 \pm 0.03 \mathrm{eV}$ and $E_{\mathrm{A}}=1.55 \pm 0.02 \mathrm{eV}$ with $E_{\mathrm{R}}=0.2 \mathrm{eV}$. To explain this change in energies with a surface temperature, two processes are proposed: either several types of adsorption sites with different detrapping energies are available on the surface or adsorbate-adsorbate repulsive interaction arises when increasing the surface coverage. The values determined for desorption energies are in good agreement with the ones reported in the literature from experiments [19, 33, 34] or first-principles calculations $[21,26,35,36]$. However, the solution energy defined as $E_{\mathrm{S}}=E_{\mathrm{A}}-E_{\mathrm{D}}+\frac{1}{2} \cdot E_{\mathrm{diss}}-E_{\mathrm{R}}$ is found to be $E_{\mathrm{S}} \approx 0.44 \mathrm{eV}-0.48 \mathrm{eV}$ for both exposure temperatures, which is much lower than the solution energy
$E_{\mathrm{S}}=1.04 \mathrm{eV}$ determined experimentally by Frauenfelder [38]. Our simulated low solution energy has been attributed to differences in the preparation of $\mathrm{W}$ samples which may affect: (i) surface contamination, e.g. with oxygen or (ii) the density of grain boundaries, which may provide preferential paths through which to enter the bulk. The acceleration of the D atoms arriving on the surface thanks to the additional potential energy, compared to $\mathrm{D}_{2}$ molecules, can also be proposed as an explanation of the low solution energy obtained in the simulations: this acceleration helps the $\mathrm{D}$ atoms to reach the energy barrier $E_{\mathrm{A}}$. However, the additional potential energy is not enough to allow incident $\mathrm{D}$ atoms to reach the bulk directly because a part of it is quickly dissipated, mainly through electron-hole pair excitation [46-48].

Using these energy barriers at the surface, our model reproduces TDS experimental spectra obtained after D atom exposures at $500 \mathrm{~K}$ very well along with the $\mathrm{D}$ depth profiles observed during the atom exposure at $600 \mathrm{~K}$ followed by isothermal desorption at the same temperature. Our results indicate that three extrinsic traps exist in these samples, in addition to the native intrinsic traps previously determined in the literature [9]. Using a pre-exponential factor of $10^{13} \mathrm{~s}^{-1}$, the corresponding detrapping energies for extrinsic traps are: $E_{\mathrm{t}, 3}=1.65 \mathrm{eV} \pm 0.01$ (trap 3), $E_{\mathrm{t}, 4}=1.85 \pm 0.03 \mathrm{eV}$ (trap 4) and $E_{\mathrm{t}, 5}=2.06 \pm 0.04 \mathrm{eV}$ (trap 5). They are in the same energy range as detrapping energies determined by previous experiments dedicated to the retention/desorption of $\mathrm{D}$ from neutron or self-damaged W $[17,49,52]$. Notably, we rationalize the absence of lower detrapping energy traps in Zaloznik and Markelj's experiments, in contrast to other experimental works, by the mobility kinetics of mono-vacancies upon annealing. By comparing these detrapping energies with DFT values for various traps $[15,53-56]$, we propose that trap 3 should be related to trapping in jogged dislocation lines filled with one to three HIs, while trap 4 should be related to dislocation loops filled with one to two HIs. These propositions are strengthened by analyses of the annealing defects presented in the literature [7]. A decrease of the concentrations of jogged dislocation lines and dislocation loops is simulated with sample annealing, similarly to STEM measurements [7]. We consider that trap 5 could be attributed to cavities (vacancy clusters), since its detrapping energy and its density evolution with annealing temperature is consistent, respectively, with DFT calculations of HIs on free surfaces and STEM measurements on $\mathrm{MeV}-\mathrm{Cu}$-damaged $\mathrm{W}$ [59]. It must also be noted that such high detrapping energies could be related to the desorption of D from D-carbon bounds that can appear in case of hydrocarbon contamination of the sample surface.

The improved MHIMS code has been used to simulate the tritium retention during several consecutive $400 \mathrm{~s}$ plasma discharges in order to estimate the tritium retention in the W divertor target of ITER [65]. In order to simulate these tokamak plasma discharges, it has to be assumed that the traps created by $14.1 \mathrm{MeV}$ neutrons are similar to the ones created by $\mathrm{W}$ ions and that the amount of traps created is similar in both cases. In the simulations presented in [65], it is also assumed that the amount of traps created by the neutron interactions is constant in the entire depth of the material and at its 
maximal value. Recent experimental results [66] pointed out that simultaneous exposures of $\mathrm{D}$ atoms and $20 \mathrm{MeV}-\mathrm{W}$ ions may affect the creation and evolution of the defects. In order to simulate such simultaneous exposures, a model for the growth of trap concentrations will have to be added to the MHIMS code. Such a trap creation model could then be used to more realistically simulate the tritium retention in $\mathrm{W}$ plasma-facing components damaged by neutrons during tokamak plasma discharges.

\section{Acknowledgment}

This work has been carried out thanks to the support of the A*MIDEX project ( ${ }^{\circ}$ ANR-11-IDEX-0001-02) funded by the 'Investissements d'Avenir' French Government program, managed by the French National Research Agency (ANR).

This work has been carried out within the framework of the EUROfusion Consortium and has received funding from the Euratom research and training programme 2014-2018 under grant agreement No 633053. Work was performed under EUROfusion WP PFC. The views and opinions expressed herein do not necessarily reflect those of the European Commission.

\section{References}

[1] Gilbert M.R. and Sublet J.C. 2011 Nucl. Fusion 51043005

[2] Ogorodnikova O.V. and Gann V. 2015 J. Nucl. Mater. 460 60-71

[3] Markelj S. et al 2014 Phys. Scr. T159 014047

[4] 't Hoen M.H.J. et al 2012 Nucl. Fusion 52023008

[5] Gasparyan Y.M. et al 2015 J. Nucl. Mater. 463 1013-6

[6] Markelj S. et al 2016 J. Nucl. Mater. 469 133-44

[7] Zaloznik A. et al 2016 Phys. Scr. T167 014031

[8] Tyburska B., Alimov V.K. and Ogorodnikova O.V. 2009 J. Nucl. Mater. 395 150-5

[9] Hodille E.A. et al $2015 \mathrm{~J}$. Nucl. Mater. 467 424-31

[10] 't Hoen M.H.J. et al 2013 Phys. Rev. Lett. 111225001

[11] Maya P.N. 2016 J. Nucl. Mater. 480 411-9

[12] Bisson R. et al 2015 J. Nucl. Mater. 467 432-8

[13] Davenport J.W. and Dienes G.J. 1982 Phys. Rev. B $252165-74$

[14] Pick M.A. and Sonnenberg K. 1985 J. Nucl. Mater. 131 208-20

[15] Fernandez N., Ferro Y. and Kato D. 2015 Acta Mater. $94307-18$

[16] Ogorodnikova O.V. 2001 Trapping effect in hydrogen retention in metals Hydrogen and Helium Recycling at Plasma Facing Materials, NATO Science Series, vol 54 ed A. Hassanein (Dordrecht: Kluwer Academic Publishers) p 7

[17] Ogorodnikova O.V., Markelj S. and Toussaint U.V. 2016 J. Appl. Phys. 119054901

[18] Juslin N. et al 2005 J. Appl. Phys. 98123520

[19] Tamm P.W. and Schmidt L.D. 1971 J. Chem. Phys. 544775
[20] Markelj S. et al 2013 Appl. Surf. Sci. 282 478-86

[21] Johnson D.F. and Carter E.A. 2010 J. Mater. Res. 25 315-27

[22] Schmid K. 2016 Phys. Scr. T167 014025

[23] Grisolia C., Ghendrih P., Pégourié B. and Grosman A. 1992 J. Nucl. Mater. 196-8 281-4

[24] Yamada Y., Rieder K.-H. and Theis W. 2007 Phys. Rev. Lett. 99196105

[25] Ziegler J.F. (online) Available: www.srim.org

[26] Heinola K. and Ahlgren T. 2010 Phys. Rev. B 81073409

[27] Moitra A. and Solanki K. 2011 Comput. Mater. Sci. 50 2291-4

[28] Roth J. et al 2013 J. Nucl. Mater. 432 341-7

[29] Longhurst G.R. 2004 TMAP-7 user manual Idaho National Laboratory Report INEEL/EXT-04-2004

[30] Causey R.A. 2002 J. Nucl. Mater. 300 91-117

[31] Lipschultz B. et al 2010 An assessment of the current data affecting tritium retention and its use to project towards $T$ retention in ITER MIT Report PSFC/RR-10-4

[32] Tanabe T. 2014 Phys. Scr. T159 014044

[33] Alnot P., Cassuto A. and King D.A. 1989 Surf. Sci. 215 29-46

[34] Nahm T.-U. and Gomer R. 1997 Surf. Sci. 375 281-92

[35] Ferrin P., Kandoi S., Udaykumar Nilekar A. and Mavrikakis M. 2012 Surf. Sci. 606 679-89

[36] Nojima A. and Yamashita K. 2007 Surf. Sci. 601 3003-11

[37] Nahm T.-U. and Gomer R. 1997 Surf. Sci. 380434

[38] Frauenfelder R. 1969 J. Vac. Sci. Technol. 6 388-97

[39] White J.A., Bird D.M. and Payne M.C. 1996 Phys. Rev. B 531667

[40] Busnengo H.F. and Martinez A.E. 2008 J. Phys. Chem. 112 5579-88

[41] Berger H.F., Resch C., Grösslinger E., Eilmsteiner G., Winkler A. and Rendulic K.D. 1992 Surf. Sci. 275 L627-30

[42] Butler D.A., Hayden B.E. and Jones J.D. 1994 Chem. Phys. Lett. 217423

[43] Engel T., Niehus H. and Bauer E. 1975 Surf. Sci. 52 237-62

[44] Oda T. 2016 Fusion Eng. Des. 112 102-16

[45] Li X.-C. et al 2011 J. Nucl. Mater. 40812

[46] Galparsoro O. et al 2016 Phys. Chem. Chem. Phys. 1831378

[47] Bünermann O. et al 2015 Science 3501346

[48] Galparsoro O. et al 2015 J. Phys. Chem. C 119 15434-42

[49] Ogorodnikova O.V. 2015 J. Appl. Phys. 118074902

[50] 't Hoen M.H.J. et al 2013 Nucl. Fusion $\mathbf{5 3} 043003$

[51] Shimada M. et al 2011 Phys. Scr. T145 014051

[52] Ogorodnikova O.V. et al $2011 \mathrm{~J}$. Nucl. Mater. 415 S661-6

[53] You Y.-W. et al 2013 AIP Adv. 3012118

[54] Xiao W. and Geng W.T. 2012 J. Nucl. Mater. 430 132-6

[55] Terentyev D. et al 2014 Nucl. Fusion 54042004

[56] Heinola K., Ahlgren T., Nordlund K. and Keinonen J. 2010 Phys. Rev. B 82094102

[57] Debelle A., Barthe M.F. and Sauvage T. 2008 J. Nucl. Mater. $376216-21$

[58] Balluffi R.W. 1978 J. Nucl. Mater. 69240

[59] Watanabe H. et al 2014 J. Nucl. Mater. 455 51-5

[60] Heinola K. and Ahlgren T. $2010 \mathrm{~J}$. Appl. Phys. 107113531

[61] Gorodetsky A.E. et al 1980 J. Nucl. Mater. 93-4 588-93

[62] Lu G.-H., Zhou H.-B. and Becquart C. S. 2014 Nucl. Fusion 54086001

[63] Küppers J. and Max-Planck-Institut für Plasmaphysik 1995 Surf. Sci. Rep. 22 249-321

[64] Hodille E.A. et al 2014 Int. J. Hydrog. Energy 39 20054-61

[65] Hodille E.A. and Grisolia C. 2017 in preparation

[66] Markelj S. et al 2016 Nucl. Mater. Energy (https://doi. org/10.1016/j.nme.2016.11.010) 